\title{
Beiträge zur Kenntnis der Zusammensetzung und des Stoffwechsels der Keimpflanzen.
}

\author{
I. \\ Von
}

E. Schulze und N. Castoro.

(Aus dem agrikulturchemischen Laboratorium des Polytechnikums in Zürich.)

(Der Redaktion zugegangen am 17. April 1903.)

\section{Einleitung.}

Die Untersuchungen, deren erster Teil der nachfolgenden Abhandlung zugrunde liegt, bilden eine Fortsetzung der von E. Schulze publizierten Arbeiten über den Eiweißumsatz in der lebenden Pflanze. ${ }^{1}$ ) Es wird zweakmäßig sein, zunächst die Gründe darzulegen, die uns zur Weiterführung dieser Untersuchungen veranlaßten, und über die dabei verfolgten Ziele uns auszusprechen.

Aus den erwähnten Arbeiten hat sich ergeben, daß beim Zerfall der Eiweißstoffe in keimenden Samen ein Stoffgemenge entsteht, welches eine große Zahl von Stickstoffverbindungen einschließt: Leucin, Aminovaleriansäure, Tyrosin, Phenylalanin, Arginin, Lysin und Histidin konnten neben Asparagin und Glutamin aus den Keimpflanzen dargestellt werden. Ferner haben jene Arbeiten zu der Schlußfolgerung geführt, daß manche der primären krystallinischen Eiweißzersetzungsprodukte im Støffwechsel der Pflänzchen eine Umwandlung erfahren, welche die Bildung von Asparagin und Glutamin zur Folge hat. Mit Hilfe dieser Schlußfolgerung läßt sich die Anhäufung von Asparagin und Glutamin in den Keimpflanzen erklären. Daß

1) Die bezüglichen Abhandlungen finden sich in dieser Zeitschrift, Bd. XXIV, S. 18-114 und Bd. XXX, S. 241-312.

Hoppe-Seyler's Zeitschrift f. physiol. Chemie. XXXVIII. 
man neben diesen Amiden bald mehr, bald weniger Leucin, Tyrosin, Arginin etc. vorfindet, erklärt sich daraus, daß diese Produkte der Eiweißzersetzung in den verschiedenen Keimpflanzenarten bald rascher, bald weniger rasch umgewandelt werden.

In Übereinstimmung mit diesen Schlußfolgerungen stehen die Ergebnisse einer im Jahre 1901 von W. Butkewitsch ${ }^{1}$ ) publizierten Arbeit. Aus dieser Arbeit hat sich ergeben, daß in keimenden Papilionaceen-Samen ein proteolytisches Enzym ${ }^{2}$ ) enthalten ist, welches das Vermögen besitzt, Eiweißstoffe unter Bildung von Leucin, Tyrosin und andern Produkten aufzulösen. Auf die Wirksamkeit dieses Enzyms ist die von Butkewits ch nachgewiesene Zunahme der Eiweißzersetzungsprodukte bei der Autodigestion der Keimpflanzen unter Zusatz antiseptischer Mittel zurückzuführen. Weder bei letzterem Vorgang, noch bei der Einwirkung des aus den Keimpflanzen abgeschiedenen Enzyms auf Eiweißstoffe konnte die Bildung von Asparagin konstatiert werden - eine Tatsache, die in Übereinstimmung mit der von E. Schulze ausgesprochenen Annahme steht, daß das Asparagin, wenn nicht ausschließlich, so doch wenigstens in der Hauptsache, ein sekundäres Produkt des Eiweißumsatzes ist. Die von Butkewitsch in Anwendung gebrachte Untersuchungsmethode erwies sich demnach als geeignet zur Kontrolle der von E. Schulze aus seinen Untersuchungen abgeleiteten Schlußfolgerungen.

Wenn auch das Wesen des in den keimenden Samen sich abspielenden Eiweißzersetzungsprozesses durch diese Arbeiten aufgeklärt worden ist, so bleibt doch auf diesem Gebiete noch vieles zu erforschen übrig. Dies gilt erstens in Bezug auf die Qualität der Keimpflanzenbestandteile. Ohne Zweifel schließen die Keimpflanzen neben den aus ihnen bisher dargestellten krystallisierenden Stickstoffverbindungen noch manche andere Stoffe solcher Art ein, deren Isolierung bis jetzt nicht

1) Diese Zeitschrift, Bd. XXXII, S. 1.

2) In Betreff der Angaben, die früher schon von Green über das Vorhandensein eines solchen Enzyms in keimenden Samen gemacht worden sind, vergleiche man die citierte Abhandlung von Butkewit sch. 
gelungen ist. Dafür sprechen außer manchen, von E. Schulze und seinen Mitarbeitern bei Ausführung ihrer Untersuchungen gemachten Beobachtungen auch noch andere Erfahrungen. Wir wissen jetzt, daß in dem bei Zersetzung der Eiweißstoffe durch Säuren entstehenden Stoffgemenge eine größere Zahl von Stickstoffverbindungen sich findet, als man früher annahm. Emil Fischer ${ }^{1}$ ) hat aus diesem Gemenge $\alpha$-Pyrrolidincarbonsäure und eine in Wasser leicht lösliche Oxyaminosäure, welche sich als Oxypyrrolidincarbonsäure herausstellte, isoliert; auch Alanin fand sich öfters vor. K. Spiro ${ }^{2}$ ) wies unter den Zersetzungsprodukten verschiedener Eiweißsubstanzen Glycocoll nach. Hopkins und Cole ${ }^{3}$ ) fanden unter den Produkten der Verdauung einer Eiweißsubstanz durch Trypsin eine nach der Formel $\mathrm{C}_{11} \mathrm{H}_{12} \mathrm{~N}_{2} \mathrm{O}_{2}$ zusammengesetzte Stickstoffverbindung, die als Indolaminopropionsäure oder als Skatolaminoessigsäure anzusehen ist. Daß diese Körper auch beim Zerfall der Eiweißstoffe in den keimenden Samen entstehen, kann zwar nicht von vornherein mit Sicherheit angenommen werden; denn es ist möglich, daß die Eiweißspaltung im pflanzlichen Organismus in einzelnen Punkten anders verläuft, als die Spaltung durch Säuren oder durch Trypsin; nachdem aber von dem bei der Spaltung durch diese Agentien entstehenden Produkten eine große Anzahl in den Keimplanzen aufgefunden worden ist, kann es doch wenigstens für wahrscheinlich erklärt werden, daß auch die übrigen bei der Spaltung der Eiweißstoffe im pflanzlichen Organismus sich bilden können. Es wird also eine Aufgabe sein, die Keimpflanzen auf das Vorhandensein dieser Stoffe zu untersuchen.

An diese Aufgabe schließt sich noch eine andere an. Nachdem man zu der Schlußfolgerung gelangt ist, daß manche der primären krystallinischen Eiweißzersetzungsprodukte in den Keimplanzen eine Umwandlung erfahren, die zur Bildung von Asparagin und Glutamin führt, muß sich die Frage aufdrängen,

1). Diese Zeitschrift, Bd. XXXIII, S. 150 u. 412, Bd. XXXV, S. 70; Berichte der D. chem. Gesellschaft, Bd. 35, S. 2660.

2) Diese Zeitschrift, Bd. XXVIII, S. 174.

3) Journ. of Physiol. (1902), 27, S. 418. 
wie diese Prozesse verlaufen. Es liegt nahe, zu vermuten; daß jene Produkte der Oxydation verfallen und daß das dabei als Abbauprodukt entstehende Ammoniak später für die synthetische Bildung der oben genannten Amide verwendet wird. Diese Hypothese ist von E. Schulze schon vor mehreren Jahren in dieser Zeitschrift ${ }^{1}$ ) ausgesprochen worden. Zu ihrer Stütze läßt sich zunächst anführen, daß in den Keimpflanzen Ammoniak in kleiner Menge auftritt und daß nach einer Angabe U. Suzukis ${ }^{2}$ ) nach Zuführung eines Ammoniaksalzes der Asparagingehalt der Pflänzchen sich vermehrt. Auch noch andere Versuche Suzukis ${ }^{3}$ ) scheinen für die Richtigkeit jener Vermutung zu sprechen. Der Genannte brachte Keimpflanzen der Gerste und der Sojabohne, die im Dunkeln erwachsen waren, teils in einen sauerstoffreien Raum, teils ließ er sie: unter Sauerstoffzutritt sich weiter entwickeln. Nur in letzterem Falle war eine Zunahme des Asparagingehalts nachzuweisen. Dies entspricht der Annahme, daß die Asparaginbildung in Keimpflanzen mit Oxydationsvorgängen zusammenhängt. Andererseits wird angegeben, daß bei Sauerstoffabschluß in der intramolekularen Atmung Asparagin gebildet wird. ${ }^{4}$ ) Diese Beobachtung ist allerdings nicht unvereinbar mit dem Resultat der Versuche Suzukis; denn es ist möglich, daß beim Zerfall der Eiweißstoffe eine gewisse Quantität von Asparagin direkt gebildet wird. Immerhin muß man es für wünschenswert erklären, zur Prüfung der obigen Hypothese noch weitere Versuche anzustellen. Es liegt nahe, in den Keimpflanzen nach Stoffen zu suchen, die man als Oxydationsprodukte der beim Eiweißzerfall direkt entstandenen Substanzen ansehen kann. Ein solcher Stoff ist von E. Schulze früher schon aufgefunden worden; es wurde nachgewiesen, daß mit dem Fortschreiten des Wachstums der Keimpflanzen ihr Gehalt an Sulfaten sich vermehrt, und es konnte wahrscheinlich gemacht

1) Bd. XXIV, S. 83-85.

2) Bull. College of Agriculture, Imperial University, Tokyo. Vol. II, Nr. 7 (1897).

3) Ebendaselbst, Vol. IV, p. 351 (1902).

4) W. Pfeffer, Pflanzenphysiologie, 2. Auflage, Bd. I, S. 464. 
werden, daß diese Sulfate bei der Oxydation einer beim Eiweißzerfall während der Keimung entstandenen Schwefelverbindung entstehen ( $\mathrm{ob}$ diese Schwefelverbindung Cystin ist, soll noch untersucht werden). Aber auch Oxydationsprodukte der beim Eiweißzerfall entstandenen Stickstoffverbindungen sind, falls jene Vermutung richtig ist, vielleicht in den Keimpflanzen aufzufinden. Nach den Untersuchungen F. Kutschers ${ }^{1}$ ) liefert das Arginin bei der Oxydation zunächst Guanidinbuttersäure, später Guanidin und Bernsteinsäure. Es muß als möglich bezeichnet werden, daß diese Stoffe auch in Keimpflanzen, in denen das Arginin dem Verbrauch unterliegt, aufzufinden sind. Guanidin ist in der Tat von E. Schulze schon früher aus etiolierten Keimpflanzen von Vicia sativa dargestellt worden ${ }^{2}$ ) auch findet es sich nach O. E. von Lippmann ${ }^{3}$ ) in kleiner Menge neben Arginin im Rübensaft vor. Es wird von Interesse sein, auch noch andere Keimpflanzen auf Guanidin zu untersuchen und zugleich zu prüfen, ob auch Bernsteinsäure sich vorfindet. ${ }^{4}$ ) Selbstverständlich aber kann das Fehlen von Guanidin noch nicht als ein Beweis dafür angesehen werden, daß das Arginin in den Keimpflanzen nicht oxydiert wird; denn es ist ja möglich, daß Guanidin zwar entsteht, aber sehr rasch weiter zerfällt und infolge davon in den Pflänzchen nicht in einer für den Nachweis genügenden Quantität enthalten ist.

Auf die Frage nach dem Schicksal des Tyrosins in den Keimpflanzen hat vor kurzem R. Bertel ${ }^{5}$ ) eine bestimmte Antwort gegeben; er schließt aus seinen an Lupinus albus gemachten Beobachtungen, daß die genannte Aminosäure unter Mitwirkung eines Enzyms in Homogentisinsäure übergeht

1) Diese Zeitschrift, Bd. XXXII, S. 413; vgl. auch Bene $\mathrm{ch}$ und Kuts cher, über die Oxydationsprodukte des Arginins, ebendaselbst, S. 278.

2) Diese Zeitschrift; Bd. XVII, S. 197.

3) Ber. d. D. chem. Gesellschaft, Bd. 29, S. 2645.

4) Es sei hier erwähnt, daß wir diese Säure in mehreren Keimpflanzen nachweisen konnten; doch braucht kaum gesagt zu werden, daß sie, außer durch Oxydation des Arginins, auch in andern Prozessen entstanden sein kann.

5) Berichte der D. Botanischen Gesellschaft, 1902, Bd. 20, S. 454: 
und daß letztere später durch Oxydation zerstört wird. Ein solcher Vorgang steht in Übereinstimmung mit der obigen Hypothese E. Schulzes; denn die Überführung des Tyrosins in Homogentisinsäure muß sich unter Sauerstoffaufnahme vollziehen und ist nach der von Wolkow und Baumann ${ }^{1}$ ) aufgestellten Gleichung mit der Bildung von Ammoniak verbunden. ${ }^{2}$ )

In den Keimpflanzen können aber auch Substanzen sich finden, die nicht einer Oxydation, sondern einem in anderer Weise erfolgten Abbau der bei der Eiweißspaltung entstandenen Produkte ihre Entstehung verdanken. So liegt es zum Beispiel im Bereich der Möglichkeit, daß als Spaltungsprodukt des Arginins Ornithin (Diaminovaleriansäure) im pflanzlichen Stoffwechsel auftritt. Als Abbauprodukt des Phenylalanins kann vielleicht Phenyläthylamin in den

1) Diese Zeitschrift, Bd. XV, S. 277.

2) Nicht unerwähnt soll bleiben, daß in neuester Zeit gegen Wolkows und Baumanns Annahmen, betreffend die Entstehung von Homogentisinsäure aus dem Tyrosin, Einwände erhoben worden sind. So hält E rich Me yer (Archiv für klin. Medizin, Bd. 70, S. 443) es für wahrscheinlich, daß das Tyrosin mit jener Säure nur indirekt im $\mathrm{Zu}$ sammenhange stehe, denn es sei chemisch nicht recht einzusehen, wie ein Übergang erfolgen könne - es müßte denn eine Atomgruppenwanderung eintreten. Auch bewirkt nach F. Mittelbach (Archiv für klin. Medizin, Bd. 71, S. 50) die Eingabe von Tyrosin nicht ein Ansteigen der Homogentisinsäure im Harn in dem von Wolkow und Baumann beobachteten Umfange (wir entnehmen diese Angaben dem Jahrbuch d. Chemie für 1901, S. 235-236). Wolkow und Baumann haben in ihren Erörterungen über die Entstehung der Homogentisinsäure aus Tyrosin die beträchtlichen Verschiedenheiten, die in bezug auf die chemische Konstitution zwischen diesen beiden Stoffen bestehen, nicht unberücksichtigt gelassen (cfr. S. 273-275 ihrer oben citierten Abhandlung); doch. scheinen ihre Darlegungen nicht jeden Zweifel zerstreut zu haben. Vor kurzem berichtete aber E. Erlenmeyer (Berichte der D. Chem. Gesellsch., Bd. 36, S. 919) über einen Vorgang, in welchem eine direkte Wanderung der Hydroxylgruppe anzunehmen ist. $\mathrm{Zu}$ erwähnen ist noch, daß Angaben über die Bildung von Homogentisinsäure aus Tyrosin in den Pflanzen zuerst von Gonnermann (Arch. f. Physiol., Bd. 82, S. 289) gemacht wurden und daß diese Säure nach Falta und Langstein (diese Zeitschr., Bd. XXXVII, S. 513) auch aus Phenylalanin entsteht. 
Pflänzchen sich finden. Auch wäre zu prüfen, ob etwa bei. der Zersetzung von Ornithin und Lysin Tetramethylendiamin und Pentamethylendiamin im Stoffwechsel der Keimpflanzen sich bilden können. Da es nun ferner möglich ist, daß nicht nur ein Abbau, sondern auch eine synthetische Bildung stickstoffhaltiger Stoffe in den Keimpflanzen stattfindet, so kann das im Saft der letzteren enthaltene Stoffgemenge eine sehr komplizierte Zusammensetzung haben.

Wie aus den im vorigen gemachten Mitteilungen sich ersehen läßt, ist die Zahl der Aufgaben, die man bei Fortführung der Untersuchungen über die qualitative Zusammensetzung der Keimpflanzen sich stellen kann, keine geringe. Die Bearbeitung dieser Aufgaben wird daher auch lange Zeit erfordern. Es ist aber hier gleich auf einen bei solchen Untersuchungen $\mathrm{zu}$ beachtenden Punkt aufmerksam zu machen. Wenn es gelingt, eines der im vorigen genannten Abbauprodukte der beim Eiweißzerfall direkt entstandenen Stoffe aus Keimpflanzen darzustellen, so kann dies für die Erforschung des Stoffwechsels der Keimpflanzen nur dann von Bedeutung sein, wenn es entweder sicher oder doch wenigstens sehr wahrscheinlich ist, daß jenes Produkt sich nicht erst während der Verarbeitung des Ausgangsmaterials gebildet hat. Man wird sich daher Mühe gehen müssen, bei Darstellung der bezüglichen Produkte Operationen zu vermeiden, welche die Zersetzung stickstoffhaltiger Pflanzenbestandteile zur Folge haben könnten.

Außer der Erweiterung unseres Wissens über die Qualität der Keimplanzenbestandteile ist aber auch eine Vermehrung und Verbesserung der über die quantitative Zusammensetzung der Keimpflanzen vorliegenden Angaben anzustreben. Daß man solcher Angaben bedarf, wenn man einen Einblick in den Verfauf des mit dem Keimungsvorgang verbundenen Eiweißumsatzes gewinnen will, ist aus den oben citierten $\mathrm{Ab}$ handlungen E. Schulzes zur Genüge zu ersehen. Die dort mitgeteilten Schlußfolgerungen gründen sich vorzugsweise auf die Ergebnisse, die bei einer Vergleichung des Stoffgehalts einer Anzahl von Keimpflanzenarten in verschiedenen Ent- 
wicklungsperioden hervortraten. Die für. den Gehalt der Untersuchungsobjekte an den verschiedenen Eiweißzersetzungsprodukten angegebenen Zahlen sind aber noch mit manchen Mängeln behaftet. Sie gründen sich zum Teil nur auf die Ausbeute, die man bei Darstellung der betreffenden Produkte aus den Keimpflanzen erhielt. Da aber diese Darstellung mit Verlusten verbunden war, und da die dabei erhaltenen Substanzen zum Teil als Rohprodukte gewogen werden mußten, so können die bezüglichen Zahlen auf Genauigkeit keinen Anspruch machen - ein Umstand, der selbstverständlich bei Ableitung der Schlußfolgerungen berücksichtigt worden ist. Daß es nun bei dieser Sachlage erwünscht sein muß, genauere Zahlen für den Gehalt der Keimpflanzen an einzelnen Eiweißzersetzungsprodukten zu gewinnen, liegt auf der Hand.

In dem im folgenden zur Publikation gelangenden ersten Abschnitt unserer Arbeit haben wir zur Lösung der meisten der oben aufgezählten Aufgaben kaum etwas beigetragen; unsere Mitteilungen betreffen hauptsächlich den Gehalt der Keimpflanzen von Lupinus albus an Asparagin, an Arginin und an Aminosäuren. Über das Ziel, das wir bei Ausführung der bezüglichen Versuche zu erreichen strebten, ist hier noch folgendes mitzuteilen:

Die von E. Schulze in bezug auf den Eiweißumsatz in den Keimpflanzen ausgesprochenen Anschauungen gründen sich vorzugsweise auf die Resultate, die bei der vergleichenden Untersuchung verschiedener Keimpflanzenarten erhalten wurden. Ist auch für die bezüglichen Versuche eine recht beträchtliche Anzahl von Keimpflanzenkulturen verwendet worden, so wurde doch fast niemals eine und dieselbe Keimpflanzenart in mehr als zwei Entwicklungsstadien auf die Qualität ihrer Bestandteile untersucht. Wir hielten es nun für wünschenswert, eine Keimpflanzenart in einer größeren Zahl von Entwicklungsstadien qualitativ und quantitativ $\mathrm{zu}$ untersuchen und die dabei erhaltenen Resultate mit denjenigen $\mathrm{zu}$ vergleichen, die sich bei Autodigestionsversuchen nach dem auch von Butkewitsch in Anwendung gebrachten Salkowskischen Verfahren ergaben. Als wichtig erschien es; bei Untersuchung der Pflänzchen neben 
dem Asparagin auch noch ein anderes Produkt des Eiweißumsatzes quantitativ zu bestimmen. Dazu eignete sich aber am besten das Arginin, da die zur Isolierung dieser Base verwendbaren Methoden durch Kossel und Kuts.cher ${ }^{1}$ ) in neuester Zeit vervollkommnet worden sind. Wir durften hoffen, auf diesem Wege Resultate zu erhalten, die sich dazu eignen würden, die in bezug auf den Eiweißumsatz in den Keimpflanzen früher schon abgeleiteten Schlußfolgerungen zu kontrollieren und vielleicht auch noch $\mathrm{zu}$ erweitern.

$\mathrm{Daß}$ wir als Objekt für unsere Untersuchung Lupinus albus wählten, hat vorzugsweise seinen Grund darin, daß mit dieser Lupinus-Art früher schon in unserem Laboratorium eine Anzahl von Versuchen, deren Ergebnisse von uns verwertet werden konnten, ausgeführt worden ist. Von E. Schulze ${ }^{2}$ ) wurden 6 tägige Keimpflanzen von Lupinus albus untersucht, von N. Wassilieff ${ }^{3}$ ) Pflänzchen, die ein nur wenig höheres Alter besaßen. Außerdem untersuchte Wassilieff (loc. cit.) 14 tägige normale, im Freien gewachsene Pflänzchen. Da diese Pflänzchen damals nicht auf Arginin untersucht worden sind, so haben wir unter Verwendung des davon noch in unseren Händen befindlichen Materials diese Base noch daraus dargestellt und ihrer Quantität nach bestimmt.

Inwieweit wir bei Ausführung unserer Untersuchung das vorgesteckte Ziel $\mathrm{zu}$ erreichen vermochten, ist aus den nachfolgenden Mitteilungen zu ersehen.

\section{Über die Zusammensetzung normaler und etiolierter Keimpflanzen von Lupinus albus.}

Die von uns verwendeten Samen von Lupinus albus waren von vorzüglicher Qualität, die daraus erhaltenen Keimpflänzchen entwickelten sich rasch und sehr gleichmäßig. Wir geben im folgenden stets das Alter der von uns untersuchten Keimpflanzenkulturen an. Doch genügt eine solche Angabe für sich allein nicht zur Kennzeichnung des Entwicklungs-

1) Diese Zeitschrift, Bd. XXXI, S. 170-175.

2) Diese Zeitschrift, Bd. XXX, S. 274-280.

3) Landwirtschaftliche Versuchsstation Bd. 55 S. 45-77. 
grades der Pflänzchen, da der letzere auch von der Temperatur usw. abhängt; wir haben daher meistens noch Angaben über die Länge des hypocotylen Glieds oder auch anderer Pflanzenteile beigefügt.

Wie schon in der Einleitung erwähnt worden ist, war es unser Bestreben, möglichst einwurfsfreie Quantitätsangaben für den Stoffgehalt der unter verschiedenen Bedingungen erwachsenen und verschiedenen Entwicklungsperioden angehörenden Pflanzen zu gewinnen. Die für diesen $Z$ weck verwendbaren Untersuchungsmethoden sind freilich, ebenso wie fast alle anderen Methoden der Pflanzenanalyse, noch unvollkommen und mit gewissen Mängeln behaftet. Dies ist bei Beurteilung der von uns mitgeteilten Versuchsergebnisse nicht zu vergessen; es mußte auch bei Ableitung der Schlußfolgerungen berücksichtigt werden.

Neben dem Gesamtstickstoff wurden in unseren Untersuchungsobjekten die auf Proteinstoffe fallende Stickstoffmenge nach Stutzers ${ }^{1}$ ) Verfahren und das Asparagin nach der Methode von Sachsse bestimmt. Ist man auch bei Anwendung des zuerst genannten Verfahrens nicht sicher, stets eine scharfe Trennung der Proteinstoffe von den übrigen Stickstoffverbindungen $\mathrm{zu}$ erreichen, so konnte doch in diesem Falle jenes Verfahren um so eher für geeignet erklärt werden, als es sich nur darum handelte, miteinander vergleichbare Zahlen für den Proteingehalt unserer Keimpflanzen zu gewinnen. Auch die nach Sachsses Methode der Asparaginbestimmung erhaltenen Resultate sind bekanntlich nicht einwandfrei und fallen in der Regel etwas zu hoch aus; daß aber die Methode bei Anwendung auf die Keimpflanzen der Lupinen brauchbare Resultate liefert, ist daraus zu schließen, daß man aus den

1) Daß wir bei Mitteilung der nach Stutzers Verfahren erhaltenen Resultate von Proteinst offen, nicht von Eiweißsubstanzen sprechen, hat zunächst seinen Grund darin, daß die erstere Bezeichnung in dem gleichen Falle auch früher in den aus unserem Laboratorium hervorgegangenen Abhandlungen gebraucht worden ist; wir verweisen außerdem auf die von E. Schulze in dieser Zeitschrift, Bd. XXIV, S. 23 gemachten Bemerkungen. 
bezüglichen Keimpflanzenextrakten durch Krystallation Asparaginquantitäten zur Abscheidung bringen kann, die nicht viel hinter den nach Sachsses Methode gefundenen Quantitäten zurückbleiben. Auch bei den Asparaginbestimmungen handelte es sich übrigens vorzugsweise darum, vergleichbare Zahlen für die verschiedenen Untersuchungsobjekte zu gewinnen.

Wie schon in der Einleitung gesagt worden ist, hielten wir es für wünschenswert, in unseren Untersuchungsobjekten neben dem Asparagin noch ein anderes Produkt des Eiweißumsatzes quantitativ zu bestimmen. Dazu eignete sich am besten das Arginin. Es trat also an uns die Aufgabe heran, möglichst einwurfsfreie Zahlen für den Arginingehalt unserer Keimpflanzen zu gewinnen. Die von E. Schulze in einer der oben citierten Abhandlungen gemachten Angaben über die aus verschiedenen Keimpflanzen erhaltene Argininausbeute bilden schon deshalb keinen genauen Ausdruck für den Arginingehalt der betreffenden Objekte, weil für die Darstellung der genannten Base nur die bei Behandlung der zerkleinerten Keimpflanzen mit kochendem Weingeist verbliebenen Rückstände, denen vielleicht durch den Weingeist schon ein kleiner Teil des Arginins entzogen war, verwendet worden sind; auch geschah die Isolierung des Arginins nach Kossels älterer Methode, welche inzwischen von Kossel und Kutscher (loc. cit.) vervollkommnet worden ist. Wir verfuhren jetzt in folgender Weise: Das wässerige Keimpflanzenextrakt wurde mit

1) Die schon früher hin und wieder aufgetauchte Angabe, daß durch das bei Ausführung des Stutzerschen Verfahrens als Fällungsmittel angewendete Kupferhydroxyd die Albumosen nur unvollständig gefällt werden, ist in neuerer Zeit entschiedener ausgesprochen worden. Ich verweise auf eine Abhandlung von Laszczinski (Zeitschrift für das gesammte Brauwesen 1899) und auf eine in unserem Laboratorium ausgeführte Arbeit Nedokutschaieffs, welche im laufenden Bande der * Landwirtschaftlichen Versuchsstationen * zur Publikation gelangen wird. Finden sich also Albumosen vor, so werden dieselben wenigstens teilweise mit den nicht proteinartigen Stickstoffverbindungen in das Filtrat vom Kupferhydroxydniederschlag übergehen. Auch abgesehen von diesem Umstande können nach Laszczinski die nach Stutzers Verfahren erhaltenen Resultate mit kleinen Fehlern behaftet sein. 
Tanninlösung versetzt, bis nur noch eine schwache Trübung entstand, der Niederschlag abfiltriert, das mit dem Waschwasser vereinigte Filtrat mit Bleiacetat, unter Vermeidung eines Überschusses von letzterem, versetzt, die vom Bleiniederschlag getrennte Flüssigkeit sodann etwas eingeengt, hierauf stark mit Schwefelsäure angesäuert und nun mit Phosphorwolframsäure versetzt, solange als dieses Reagens sofort einen Niederschlag hervorbrachte. Diesen Niederschlag zerlegten wir, nachdem er auf einer Nutsche abfiltriart und mit 5\% iger Schwefelsäure ausgewaschen worden war, in bekannter Weise durch Verreiben mit kaltem Wasser und Baryumhydroxyd, befreiten die dabei erhaltene Basenlösung in früher beschriebener Weise vom Ammoniak und neutralisierten sie sodann mit Salpetersäure; hierauf fällten wir aus ihr zuerst das Histidin, dann das Arginin nach Kossels und Kutschers Vorschrift durch Silbernitrat ${ }^{1}$ ) und Barytwasser aus. Der Argininsilberniederschlag wurde so behandelt, wie es von den genannten Forschern vorgeschrieben ist, das Arginin demgemäß in das salpetersaure Salz übergeführt.

Da für die Abscheidung des Arginins aus den Keimpflanzen bisher Kossels älteres Verfahren verwendet wurde, so haben wir, um der Anwendbarkeit der neueren Methode für den vorliegenden Zweck sicher zu sein; einige Versuche mit den argininreichen Keimpflanzen vom Lupinus luteus angestellt. In diesen Versuchen ließ sich die Trennung des Arginins vom Histidin nach Kossels und Kutschers Vorschrift ohne Schwierigkeit bewerkstelligen; die bei der Verarbeitung des Silberniederschlags erhaltene Argininlösung lieferte nach der Neutralisation mit Salpetersäure beim Verdunsten eine weiße Krystallmasse von Argininnitrat, in welcher das Vorhandensein von Mutterlauge nicht mehr zu bemerken war. Dieses Produkt war ohne Zweifel fast völlig rein; aus seiner mit Kupferhydroxyd gesättigten Lösung schied sich nach dem Erkalten sofort das Argininkupfernitrat in den charakteristischen

1) Eine Fällung, die durch Silbernitrat allein (ohne Barytwasserzusatz) hervorgebracht wurde, entfernten wir zuvor durch Filtration. Dies geschah auch in den im Abschnitt D mitgeteilten Bestimmungen. 
Formen aus, der Schmelzpunkt der so erhaltenen Krystalle lag bei $112-114^{\circ}$ und entsprach also der von Gulewitsch gemachten Angabe. Der Arginingehalt der in dieser Weise untersuchten 11-12tägigen etiolierten Pflänzchen von Lupinus luteus betrug im Mittel 2,9\%, berechnet aus dem Gewicht des in der beschriebenen Weise erhaltenen Argininkupfernitrats.

Nicht ganz den gleichen Reinheitsgrad besaß das Argininnitrat, welches nach dem gleichen Verfahren aus den Keimpflanzen von Lupinus albus erhalten wurde. Dies kann kaum auffallen. Die Keimpflanzen von Lupinus albus sind weit ärmer an Arginin, als diejenigen von Lupinus luteus. Die in sehr kleiner Menge vorhandenen Substanzen, welche bei der Abscheidung des Arginins aus den Extrakten diese Base begleiten, fallen demnach bei jenen Pflänzchen im Verhältnis zum Arginin weit mehr ins Gewicht, als bei diesen. Wir haben daher den Arginingehalt der Pflänzchen nicht aus dem Gewicht des erhaltenen Argininnitrats berechnet, sondern das letztere stets in das Argininkupfernitrat übergeführt. Diese in kaltem Wasser schwer lösliche Verbindung wurde so vollständig wie möglich zur Krystallisation gebracht, von der Mutterlauge durch Waschen mit einer kleinen Menge kalten Wassers und Absaugen mit Filtrierpapier befreit, sodann getrocknet und gewogen. Das Gewicht der Krystalle wurde bei der Berechnung des Arginingehalts der Pflänzchen zugrunde gelegt. Es ist klar, daß die in solcher Weise erhaltenen Zahlen etwas zu niedrig ausfallen müssen, denn bei der Darstellung des Arginins sind kleine Verluste nicht zu vermeiden. Schon die Ausfällung der Base durch Phosphorwolframsäure ist mit einem kleinen Verluste verbunden, weil der Niederschlag auch bei Gegenwart von Schwefelsäure nicht absolut unlöslich in kaltem Wasser ist; das Gleiche gilt für die Gewinnung des Argininkupfernitrats. Ist auch diese Verbindung in reinem Zustande sehr schwer löslich in kaltem Wasser, so löst sie sich darin doch etwas mehr, falls Beimengungen vorhanden sind. Sind aber auch die für den Arginingehalt unserer Keimpflanzen angegebenen Zahlen etwas zu niedrig, so unterliegt es doch keinem Zweifel, daß sie mit 
einander vergleichbar sind, da die ihnen anhaftenden Fehler stets in der gleichen Richtung liegen. Für den Zweck unserer Arbeit war es aber nur erforderlich, mit einander vergleichbare Zahlen zu gewinnen.

Das in der beschriebenen Weise aus unseren Untersuchungsobjekten gewonnene und zur Wägung gebrachte Argininkupfernitrat war im übrigen fast völlig rein. Nach einmaligem Umkrystallisieren aus Wasser besaß es den richtigen Schmelzpunkt $\left(112-114^{\circ}\right)$. Der Kupfergehalt ist in mehreren Präparaten bestimmt worden, wie aus den weiter unten folgenden Angaben sich ersehen läßt. Die übrigen Präparate wurden vereinigt und sodann einmal aus Wasser umkrystallisiert; der Kupfergehalt des so gewonnenen Produkts wurde nach Entfernung des Krystallwassers $=11,93 \%$ gefunden, während die Theorie $11,89 \%$ verlangt.

Es war ursprünglich unsere Absicht, auch den Histidingehalt unserer Untersuchungsobjekte zu bestimmen. Wir behandelten daher den in oben angegebener Weise erhaltenen Histidinsilberniederschlag nach der von Kossel und Kutscher (loc. cit.) gegebenen Vorschrift und brachten das Histidin als Dichlorid zur Wägung. Dieses Produkt war aber fast immer dunkel gefärbt, auch entsprach der Silbergehalt des daraus dargestellten Histidinsilbers nicht genau der Theorie. Es scheint demnach, daß jenes Verfahren zur Reindarstellung des Histidins sich auf die Keimpflanzenextrakte nicht so gut anwenden läßt, wie auf die bei Zersetzung der Eiweißstoffe durch Säuren erhaltenen Lösungen. Demgemäß teilen wir die für den Histidingehalt unserer Objekte erhaltenen Zahlen nur in einigen Fällen und nur unter Vorbehalt mit. Übrigens war es für den in unserer Arbeit verfolgten Zweck nicht besonders wichtig, auch den Histidingehalt unserer Keimpflanzen zu bestimmen. Denn einerseits tritt beim Zerfall der pflanzlichen Eiweißstoffe das Histidin in weit geringerer Menge auf, wie das Arginin und andererseits geht schon aus den früher ausgeführten Untersuchungen hervor, daß die erstere Base im Stoffwechsel der Keimpflanzen eine ziemlich große Beständigkeit zeigt. 
Eine Quantitätsbestimmung der in den Keimpflanzen sich findenden Aminosäuren (Leucin, Aminovaleriansäure, Tyrosin, Phenylalanin) läßt sich mit den zur Zeit zur Verfügung stehenden Mitteln nicht in genauer Weise ausführen. Die Zahlen, welche für die aus den Keimpflanzen erhaltene Ausbeute an Aminosäuren im folgenden und in früher publizierten Abhandlungen angegeben sind, bleiben ohne Zweifel hinter den in den betreffenden Objekten wirklich enthaltenen Quantitäten von Aminosäuren bedeutend zurück, weil die letzteren aus den Extrakten, auch wenn man diese in der von E. Schulze angegebenen Weise dargestellt und gereinigt hat, nur unvollständig auskrystallisieren.

Für die Quantitätsbestimmungen verwendeten wir, insoweit im folgenden nicht ausdrücklich das Gegenteil angegeben ist, bei einer Temperatur von $60-70^{\circ}$ getrocknete Keimpflanzen; doch ließen wir die Pflänzchen meistens vor dem Einbringen in den Trockenschrank einen halben Tag lang an der Luft liegen, um einen Teil des Vegetationswassers zu entfernen. In dem mit gutem Luftzug versehenen geräumigen. Trockenschrank wurden sie dann in dünner Schicht ausgebreitet, sodaß das Entweichen des Wassers rasch erfolgen konnte. Das bekanntlich allgemein übliche Verfahren, die für quantitative Bestimmungen zu verwendenden Pflanzen oder Pflanzenteile bei dem oben angegebenen oder einem ähnlichen Wärmegrad zu trocknen, kann unter Umständen Fehler bedingen, denn es liegt im Bereich der Möglichkeit, daß die erhöhte Temperatur nicht bloß das Wasser zur Verdunstung bringt, sondern in den Pflanzen auch noch andere Veränderungen bewirkt - ein Umstand, auf welchen E. Schulze früher schon hingewiesen hat. Beim Trocknen in der Wärme verändern die Pflanzen in der Regel mehr oder weniger ihre Farbe; wässerige oder weingeistige Extrakte aus den getrockneten Pflanzen besitzen meistens eine dunkle Färbung, während Extrakte aus frischen Pflanzen in der Regel, falls nicht etwa lösliche Farbstoffe oder Chromogene vorhanden sind, farblos oder nur schwach gefärbt sind; sie färben sich aber meistens, wenn man sie in der Wärme stark einengt. Man darf an- 
nehmen, daß diese Färbungen teilweise auf eine Veränderung der vorhandenen Kohlenhydrate zurückzuführen sind, denn es ist ja bekannt, daß Kohlenhydratlösungen, die durch andere Substanzen stark verunreinigt sind, während des Eindunstens sich meistens stark bräunen. Es muß nun wohl als unwahrscheinlich bezeichnet werden, daß die stickstoffhaltigen Bestandteile der Pflanzen von den durch die Erhöhung der Temperatur hervorgebrachten Veränderungen in keiner Weise betroffen werden. So ist es z. B. möglich, daß durch die in den Pflanzensäften enthaltenen Säuren ein geringer Teil des Asparagins oder Glutamins unter Bildung von asparaginsaurem bezw. glutaminsaurem Ammonium zersetzt wird. Ferner ist darauf aufmerksam $\mathrm{zu}$ machen, daß frische, noch lebende Pflanzen nach dem Einbringen in einen auf $60-70^{\circ}$ erwärmten Trockenschrank erst nach Verlauf einer gewissen, freilich nicht langen Zeit, jene Temperatur annehmen und dadurch getötet werden; es werden demnach in ihnen gewisse physiologische Prozesse, wenigstens eine ganz kleine Zeit hindurch sich bei erhöhter Temperatur vollziehen. Zudem ist nicht $z u$ erwarten, daß durch das Absterben der Pflanzen die durch Enzyme hervorgebrachten Stoffumwandlungen sofort vollständig sistiert werden. $\mathrm{Zu}$ den Prozessen solcher Art gehört auch die durch proteolytische Enzyme bewirkte Spaltung der Eiweißstoffe. Bei einer Temperatur von $60-70^{\circ}$ wird allerdings die Wirksamkeit solcher Enzyme sehr stark abgeschwächt sein; auch liegt auf der Hand, daß diese Wirksamkeit ihr Ende erreichen muß, sobald infolge des Austrocknens der Feuchtigkeitsgehalt der Pflanzen auf ein sehr geringes Maß gesunken ist. Man würde selbstverständlich die Wirksamkeit der Enzyme ganz vernichten können, wenn man die Pflanzen in einen auf nahezu $100^{\circ}$ geheizten Trockenschrank brächte; doch empfiehlt sich dies deshalb nicht, weil dann die Gefahr größer ist, daß durch die erhöhte Temperatur für sich allein gewisse Pflanzenbestandteile während des Austrocknens eine Veränderung erleiden.

Die im vorigen gemachten Erörterungen geben keine genügende Grundlage für die Entscheidung der Frage, wie groß. die Veränderungen sind, denen während des Austrocknens der 
Pflanzen die Bestandteile der letzteren unterliegen. Wir haben es daher für angezeigt gehalten, darüber einige Versuche anzustellen. Von den der gleichen Kultur angehörenden Keimpflanzen wurde ein Teil im Trockenschrank bei ca. $65^{\circ}$ getrocknet, die übrigen Pflänzchen wurden in kalten Alkohol geworfen, nach mehrwöchentlichem Verweilen unter letzterem $^{1}$ ) herausgenommen und im Exsiccator über konzentrierter Schwefelsäure ausgetrocknet, wobei sie sich in eine leicht zerreibliche, wenig gefärbte Masse verwandelten. In jedem dieser beiden Objekte wurde dann der «Proteinstickstoff» nach Stutzers Methode, in den in der Wärme getrockneten auch der Gesamtstickstoff bestimmt. Bei Analyse der mit Hilfe von Alkohol entwässerten Pflänzchen mußte selbstverständlich auch der Substanzgehalt der alkoholischen Flüssigkeit berücksichtigt werden; der für eine Bestimmung zu verwendenden Quantität der trockenen Pflänzchen wurde der Verdampfungsrückstand des zugehörigen Anteils der alkoholischen Flüssigkeit zugefügt. Neben den auf diesem Wege für zwei Keimpflanzenkulturen erhaltenen Resultaten teilen wir im folgenden die Zahlen mit, welche in der gleichen Weise früher für Keimpflanzen von Lupinus luteus sich ergeben haben. ${ }^{2}$ ) Alle Zahlen beziehen sich auf die Keimpflanzentrockensubstanz.

\begin{tabular}{|c|c|c|c|c|}
\hline & \multirow{2}{*}{\multicolumn{2}{|c|}{$\begin{array}{l}\text { Gesamt- } \\
\text { stickstoff }\end{array}$}} & \multicolumn{2}{|c|}{ Proteinstickstoff } \\
\hline . & & & $\begin{array}{c}a \\
\text { Bei } 65^{\circ} \\
\text { getrocknete } \\
\text { Pflänzchen }\end{array}$ & $\begin{array}{c}\text { b } \\
\text { Unter Alkohol } \\
\text { entwässerte } \\
\text { Pflänzchen }\end{array}$ \\
\hline Viertägige Keimpfl. & v. Lup. alb. & 8,37 & 5,86 & 6,11 \\
\hline Elftägige & $\triangleright>$ & 9,12 & 3,09 & 3,29 \\
\hline Sechstägige & $\bowtie$ luteus & 9,83 & 5,78 & 5,98 \\
\hline
\end{tabular}

Die Differenzen zwischen den unter a und unter $\mathrm{b}$ aufgeführten Zahlen sind, wie man sieht, nur gering. Sie lassen sich vielleicht schon aus den unvermeidlichen Versuchsfehlern erklären, deren Betrag in diesem Falle nicht zu niedrig geschätzt werden darf. Denn für die vergleichenden Bestimmungen konnten ja nicht die gleichen Pfänzchen, sondern nur

1) Der zuerst aufgegossene Alkohol wurde nach einiger Zeit durch frischen ersetzt.

2) Man vergleiche diese Zeitschr., Bd. XXIV, S. 43.

Hoppe-Seyler's Zeitschrift f. physiol. Chemie. XXXVIII. 
verschiedene Pflänzchen der gleichen Kultur benutzt werden; es ist aber möglich, daß diese Pflänzchen in ihrem Entwicklungsgrade nicht genau übereinstimmten und infolge davon auch kleine Verschiedenheiten im Stoffgehalt zeigten. Immerhin kann der Umstand, daß in den in der Wärme getrockneten Pflänzchen in allen drei Fällen etwas weniger Proteinstickstoff gefunden wurde, als in den unter Alkohol entwässerten Pflänzchen, dahin gedeutet werden, daß beim Trocknen in der Wärme noch ein wenig Protein zerfällt. Mit Sicherheit läßt sich aber wegen der möglichen Versuchsfehler diese Schlußfolgerung nicht ableiten. Auch liegt es im Bereich der Möglichkeit, daß dieser Zerfall, falls derselbe überhaupt stattfindet, nur peptonartige Produkte liefert.

Wir haben uns nicht auf die oben mitgeteilten Versuche beschränkt, sondern auch in Keimpflanzen, von denen die eine Hälfte (a) bei ca. $65^{\circ}$ getrocknet, die andere (b) unter Alkohol entwässert worden war, den Gehalt an Arginin in der oben beschriebenen Weise bestimmt. Dabei ergaben sich folgende Resultate:

1. $244,4 \mathrm{~g}$ Trockensubstanz von a gaben $1,129 \mathrm{~g}$ Argininkupfernitrat $=0,666 \mathrm{~g}$ oder $0,27 \%$ Arginin.

2. $218,2 \mathrm{~g}$ Trockensubstanz von b gaben $1,0814 \mathrm{~g}$ Argininkupfernitrat $=0,638 \mathrm{~g}$ oder $0,29 \%$ Arginin.

Aus den beiden Objekten wurde also pro 100 Teile Trockensubstanz fast genau die gleiche Argininmenge erhalten.

Die Keimpflanzen von Lupinus albus enthalten nicht viel Arginin; es schien daher angezeigt, auch noch einen entsprechenden Versuch mit den an Arginin weit reicheren Pflänzchen von Lupinus luteus zu machen. Darüber liegen allerdings schon Angaben von E. Schulze vor', derselbe erhielt aus den unter Alkohol entwässerten Cotyledonen etiolierter Keimpflanzen von Lupinus luteus 7,8\% Argininnitrat; ungefähr die gleiche Ausbeute erhielt er aber mehrmals auch aus den in der Wärme getrockneten Cotyledonen solcher Keimpflanzen. Doch sind diese Zahlen nicht vollkommen beweiskräftig, weil sie sich auf die Cotyledonen verschiedener Keimpflanzenkulturen beziehen und weil die Abscheidung des Arginins 
nach dem älteren Verfahren, welches zunächst ein nicht ganz reines Produkt lieferte, geschah. Wir haben daher noch einen Versuch in folgender Weise angestellt: von elf- bis zwölftägigen Keimpflanzen von Lupinus luteus wurde die Hälfte (A) im Trockenschrank bei $65^{\circ}$ getrocknet, die andere Hälfte (B) in der oben näher beschriebenen Weise unter Alkohol entwässert. Aus jedem dieser beiden Objekte wurde dann nach der oben mitgeteilten Vorschrift das Arginin isoliert. Wir erhielten dabei folgende Resultate:

A. $\beta 3 \check{0}, 21 \mathrm{~g}$ Pflanzentrockensubstanz lieferten $1,636 \mathrm{~g}$ Argininkupfernitrat $=0,9659 \mathrm{~g}$ oder $2,744^{\circ} 0$ Arginin.

B. $36,71 \mathrm{~g}$ Pflanzentrockensubstanz lieferten $1,931 \mathrm{~g}$ Argininkupfernitrat $=1,140 \mathrm{~g}$ oder $3,10 \%$ Arginin.

Die unter Alkohol entwässerten Pflänzchen haben somit etwas mehr Arginin geliefert, als die in der Wärme getrockneten, doch ist die Differenz nicht groß und läßt sich wohl auf die unvermeidlichen Versuchsfehler zurückführen. Denn abgesehen davon, daß bei Anwendung eines Verfahrens, wie wir es zur Darstellung des Arginins benutzten, die Resultate stets gewisse Schwankungen zeigen werden, kommt noch in Betracht, daß hier für die vergleichenden Versuche nicht die gleichen Pflänzchen, sondern nur verschiedene Pflänzchen der gleichen Kultur verwendet werden konnten; es ist aber möglich, daß zwischen denselben in bezug auf den Entwicklungsgrad und demgemäß auch in bezug auf den Arginingehalt kleine Verschiedenheiten bestanden. Solche Verschiedenheiten konnten hier um so eher einen Einfluß ausüben, als die für diesen Versuch verwendete Anzahl von Pflänzchen nicht sehr groß war (das Gesamtgewicht der trockenen Pflänzchen betrug nur ca. $80 \mathrm{~g}$, während für die entsprechenden Versuche mit Lupinus albus weit größere Quantitäten verwendet wurden).

Die im vorigen mitgeteilten Versuchsergebnisse schließen die Annahme aus, daß der Arginingehalt der Keimpflänzchen während des Trocknens bei $65-70^{\circ}$ sich vermehrt; eher lassen sie es als möglich erscheinen, daß während des Trocknens ein wenig Arginin zersetzt wird. Doch kann diese Schlußfolgerung nicht bestimmt ausgesprochen werden, da 
die von uns besbachteten Differenzen in der Argininausbeute nur gering waren.

In unseren Versuchen machte es also nur einen kleinen Unterschied, ob wir die Pflänzchen in der Wärme vom Wasser befreiten oder ob wir sie in Alkohol warfen und nach dem Abgießen der weingeistigen Flüssigkeit über Schwefelsäure bei Zimmertemperatur trockneten. Allerdings haben wir bei Untersuchung dieser Pflänzchen neben dem "Proteinstickstoff » nur eines der krystallinischen Eiweißzersetzungsprodukte, nämlich das Arginin, bestimmt. Was die aus den Keimpflanzen bis jetzt abgeschiedenen Aminosäuren, nämlich das Leucin, die Aminovaleriansäure, das Tyrosin und das Phenylalanin, betrifft, so ist es unwahrscheinlich, daß dieselben während des Trocknens der Pflänzchen bei $60-70^{\circ}$ durch die Wirksamkeit eines Enzyms an Menge in einem in Betracht kommenden Maße zugenommen haben. Findet ein solcher Prozeß statt, so muß derselbe ja in seiner Wirkung besonders dann hervortreten, wenn man ganz junge Keimpflanzen bei $35-40^{\circ}$ trocknet. Wie aus den weiter unten gemachten Mitteilungen $\mathrm{zu}$ ersehen ist, enthielten aber die in dieser Weise getrockneten zweitägigen Pflänzchen, die wir als Material für die Autodigestionsversuche verwendeten, nur eine sehr kleine Quantität von Leucin und Tyrosin (dies erklärt sich daraus, daß das proteolytische Enzym nur sehr langsam wirkt). Im Hinblick auf die große Beständigkeit der oben genannten Aminosäuren ist es ferner auch sehr unwahrscheinlich, daß dieselben beim Trocknen der Pflänzchen in der Wärme eine Veränderung erleiden. Eher wäre, wie oben schon erwähnt wurde, eine solche Veränderung für das unter Ammoniakabspaltung leicht zersetzbare Asparagin möglich; daß dieselbe aber nur in sehr geringem Grade erfolgt, lehrt die Tatsache, daß getrocknete etiolierte Lupinus-Keimpflanzen neben sehr viel Asparagin nur sehr wenig Ammoniak enthalten und daß letzteres auch in den frischen Keimpflanzen nachzuweisen, also nicht seinem ganzen Betrage nach aus Asparagin abgespalten ist. Wenn es auch nach Ausführung der beschriebenen Versuche kaum nötig war, noch den Beweis dafür zu liefern, daß 
man auch aus den frischen, nicht getrockneten Pflänzchen Argin in darstellen kann, so haben wir doch noch einen bezüglichen Versuch ausgeführt. Frische 4tägige Keimpflanzen von Lupinus albus wurden unter Zusatz von etwas Wasser zerkleinert und sodann zur Gewinnung des Saftes ausgepreßt, der Rückstand mit heißem Wasser übergossen und nach ca. einer Stunde wieder abgepreßt. Den in dieser Weise gewonnenen verdünnten Saft versetzten wir mit Tannin, dann mit Bleizucker, entfernten die dabei entstandenen Niederschläge durch Filtration, säuerten das Filtrat mit Schwefelsäure stark an und versetzten es hierauf mit Phosphorwolframsäure. Den durch dieses Reagens hervorgebrachten Niederschlag verarbeiteten wir in der oben angegebenen Weise auf Arginin. Wir erhielten folgendes Resultat:

$1100 \mathrm{~g}$ frische Pflänzchen, $=188 \mathrm{~g}$ wasserfrei, gaben $0,660 \mathrm{~g}$ Argininkupfernitrat $=0,389 \mathrm{~g}$ Arginin. 100 Teile Trockensubstanz gaben also 0,21 Teile Arginin.

Die Ausbeute an Arginin war also etwas niedriger als aus den getrockneten Pflänzchen gleichen Alters, doch sind die Zahlen nicht direkt vergleichbar, weil die frisch verarbeiteten Pflänzchen einer anderen Kultur entstammten.

Aus 4tägigen frischen Keimpflanzen ließ sich auch leicht Tyrosin abscheiden. Der in oben beschriebener Weise gewonnene verdünnte Saft wurde mit Phosphorwolframsäure versetzt, der Niederschlag abfiltriert, das Filtrat durch Bleiessig vom Phosphorwolframsäureüberschuß und den anderen, durch Bleilösung fällbaren Substanzen befreit, dann mit Mercurinitratlösung vermischt. Der durch dieses Reagens hervorgebrachte Niederschlag wurde nach mehrtägigem Stehen abfiltriert und ausgewaschen, dann in Wasser verteilt und durch Schwefelwasserstoff zersetzt. Die vom Schwefelquecksilber abfiltrierte Lösung lieferte, nachdem sie mit Ammoniak neutralisiert und stark eingeengt worden war, Krystalle von Tyrosin und von Asparagin. Die ersteren ließen sich durch Abschlemmen von den gröberen Asparaginkrystallen größtenteils trennen und sodann durch Umkrystallisieren reinigen; sie gaben sowohl die Hoffmannsche als die Piriasche Reaktion. 
Im folgenden besprechen wir zunächst die Zusammensetzung der ungekeimten Samen von Lupinus albus, dann die Zusammensetzung der Keimpflanzen in ihren verschiedenen Entwicklungsstadien.

\section{A. Die ungekeimten Samen.}

In den ungekeimten, von den Schalen befreiten Samen von Lupinus albus fand Wassilieff 7,68\% Stickstoff; auf Proteinstoffe fielen nach der nach Stutzers Methode ausgeführten Bestimmung 6,89\% Stickstoff. Der Rest $(0,79 \%)$ gehörte zum größern Teile Verbindungen an, die durch Phosphorwolframsäure fällbar sind (unter denselben finden sich Alkaloide); auf Verbindungen anderer Art fielen nur 0,26\% Stickstoff. Diese Prozentzahlen beziehen sich sämtlich auf die Trockensubstanz der entschälten Samen.

$\mathrm{Da}$ in den ungekeimten Samen auf Verbindungen, die nicht durch Phosphorwolframsäure gefällt wurden, nur 0,26 \% Stickstoff fiel, so können diese Samen Asparagin und Aminosäuren, falls solche Stoffe überhaupt vorhanden waren, nur in sehr kleiner Menge enthalten haben. Ein von uns angestellter Versuch, aus diesen Samen nach den auch auf die Keimpflanzen angewendeten Verfahren Aminosäuren abzuscheiden, lieferte bei Anwendung von $1 \mathrm{~kg}$ feinzerriebener Samen ein negatives Resultat; wir erhielten nur einen Sirup, aus welchem nichts krystallisierte. Doch kann aus diesem Resultat noch nicht auf völlige Abwesenheit von Aminosäuren geschlossen werden; es ist möglich, daß eine kleine Menge davon sich vorfand, aber durch Beimengungen am Auskrystallisieren gehindert wurde. Wir haben daher noch einen Versuch angestellt, um auf Tyrosin und zugleich auf Asparagin zu prüfen. Ein Quantum von $500 \mathrm{~g}$ der zerkleinerten Samen wurde mit heißem Wasser extrahiert, der Auszug von den durch Phosphorwolframsäure und durch Bleiessig fällbaren Bestandteilen befreit und sodann mit Mercurinitrat versetzt. Der durch dieses Reagens erzeugte Niederschlag wurde, nach dem Abfiltrieren und Auswaschen, durch Schwefelwasserstoff zerlegt. Eine Probe der vom Schwefelquecksilber abfiltrierten sauren Flüssigkeit 
gab nach dem Kochen keine deutliche Ammoniakreaktion mit Nesslerschem Reagens und kann demnach Asparagin höchstens in Spuren enthalten haben. Als diese Flüssigkeit mit Ammoniak neutralisiert und dann stark eingeengt wurde, lieferte sie eine sehr geringe Quantität einer in Wasser sehr schwer löslichen Substanz, die beim Erhitzen mit Millonschem Reagens eine rote Lösung gab. Wahrscheinlich war diese Substanz Tyrosin, doch war ihre Quantität so gering, dạß die Frage nach ihrer Natur nicht durch Anstellung anderer Reaktionen entschieden werden konnte.

Mit Sicherheit ließ sich das Vorhandensein einer kleinen Menge von Arginin im Samenextrakt nachweisen. Für den bezüglichen Versuch verwendeten wir $1 \mathrm{~kg}$ der lufttrockenen zerkleinerten Samen. Letztere wurden zunächst mit heißem Weingeist behandelt. Der dabei entstandene Auszug, welcher kein Arginin lieferte, wurde beseitigt. Den in Weingeist unlöslichen Teil der Samen behandelten wir mit heißem Wasser, befreiten den Auszug von den durch Tannin und durch Bleiessig fällbaren Bestandteilen und versetzten ihn sodann, nachdem er mit Schwefelsäure stark angesäuert war, mit Phosphorwolframsäure. Bei der Verarbeitung nach der oben mitgeteilten Vorschrift lieferte der Phosphorwolframsäureniederschlag eine kleine Menge von fast völlig reinem Argininnitrat. Dasselbe wurde in Argininkupfernitrat übergeführt. Diese Verbindung krystallisierte in den charakteristischen Formen, die Krystalle schmolzen bei $112-114^{\circ}$. Das daraus wiedergewonnene neutrale Nitrat gab die Reaktionen des Argininnitrats. Die Ausbeute an Arginin war nur gering; 1 Kilo der lufttrockenen Samen lieferte nur 0,2312 g Argininkupfernitrat $=0,1364 \mathrm{~g}$ Arginin. Berechnet für die schalenfreie Samentrockensubstanz beträgt die Ausbeute an Arginin nur 0,019 \%.

$\mathrm{Daß}$ in den ungekeimten Samen von Lupinus albus Eiweißzersetzungsprodukte nicht völlig fehlten, kann nicht auffallen, nachdem im Embryo des ruhenden Weizenkorns Asparagin und Allantoin in kleiner Menge nachgewiesen worden sind. Vielleicht finden sich Produkte solcher Art bei den LupinusSamen nur im Blatt- und Wurzelkeim vor. 
Da wir bei Untersuchung der Keimpflanzen von Lupinus albus stets dem Gehalt an Arginin unsere Aufmerksamkeit geschenkt haben, so war es von Interesse, festzustellen, wie viel Arginin die Eiweißsubstanz der Samen von Lupinus albus bei der Spaltung durch Salzsäure lieferte. Wir haben daher diese Eiweißsubstanz (dargestellt durch wiederholte Behandlung der fein zerriebenen, entfetteten Samen mit höchst verdünnter Natronlauge und Versetzen dieser alkalischen Extrakte mit Essigsäure) durch 10stündiges Kochen mit starker Salzsäure zersetzt. Aus der Lösung fällten wir die basischen Produkte durch Phosphorwolframsäure aus. Der Niederschlag wurde, nachdem er sorgfältig ausgewaschen worden war, mit Baryumhydroxyd zersetzt, die dabei erhaltene Basenlösung nach den von Kossel und Kutscher gegebenen Vorschriften auf Arginin, Histidin und Lysin verarbeitet. Aus $60 \mathrm{~g}$ der lufttrockenen Eiweißsubstanz ( $=58,46 \mathrm{~g}$ wasserfreie Substanz) erhielten wir 1,75 g Histidindichlorid, 8,55 g Argininkupfernitrat und 2,54 g Lysinpikrat. Demnach lieferten 100 Teile der wasserfreien Eiweißsubstanz

$$
\begin{aligned}
& 2,00 \text { Teile Histidin, } \\
& 8,64 \text { D Arginin, } \\
& \mathbf{1 , 5 2}>\text { Lysin. }
\end{aligned}
$$

Vergleicht man diese Ausbeute mit derjenigen, die von E. Schulze und E. Winterstein aus der Eiweißsubstanz der Samen von Lupinus luteus erhalten wurde, so ergibt sich, daß die letztere Eiweißsubstanz weniger Histidin und weniger Arginin, dagegen mehr Lysin lieferte, als das von uns verwendete Eiweißpräparat aus den Samen von Lupinus albus.

\section{B. Keimpflanzen der ersten Entwicklungsperiode.}

Als Keimpflanzen der I. Periode bezeichnen wir Pflänzchen, deren Alter höchstens 7 Tage beträgt. Wie man weiß, ist es für die Entwicklung der Pflänzchen gleichgültig, ob man in den ersten Tagen nach Beginn der Keimung das Licht zutreten läßt, oder dasselbe abschließt.

E. Schulze ${ }^{1}$ ) untersuchte 6tägige Keimpflanzen von

1) Diese Zeitschr., Bd. XXX, S. 274 ff. 
Lupinus albus, welche im Freien in fruchtbarer Erde gewachsen waren, aber sich ziemlich langsam entwickelt hatten. Aus den Cotyledonen dieser Pflänzchen konnten Leucin, Tyrosin und Hexonbasen dargestellt werden; die übrigen Pflanzenteile lieferten ein Aminosäurengemenge, in welchem Aminovaleriansäure sich nachweisen ließ.

Wir untersuchten jetzt noch 4tägige Pflänzchen, die in einem Zimmer unseres Instituts bei einer von $20^{\circ} \mathrm{C}$. nicht weit abweichenden Temperatur in Sand gewachsen waren; trotz der kürzeren Vegetationszeit hatten sie ungefähr den gleichen Entwicklungsgrad erreicht, wie die vorher erwähnten 6tägigen Pfänzchen; das hypocotyle Glied besaß bei ihnen eine Länge von ca. $1,5 \mathrm{~cm}$. Bei Untersuchung dieser Pflänzchen erhielten wir folgende Zahlen:

Die Keimpflanzentrockensubstanz enthielt:

Gesamtstickstoff $8,37 \%$,

Proteinstoffe $\quad 35,16 \%$ mit $5,86 \% \mathrm{~N}$,

Asparagin $\quad 3,11 \%$, $1,32 \%$,

Arginin $\quad 0,28 \%$ > $0,09 \%$, 1)

In den Pflänzchen einer andern Kultur, deren Entwicklungsgrad ungefähr der gleiche war, wurden 0,21\% Arginin gefunden, wobei zu bemerken ist, daß diese Pflänzchen nicht getrocknet, sondern in frischem Zustande verarbeitet worden sind.

Nicht viel anders scheint der Arginingehalt der von E. Schulze untersuchten 6 tägigen Keimpflanzen gewesen zu sein; derselbe berechnet sich aus den in der bezüglichen Abhandlung sich findenden Daten auf ungefähr 0,2 \%.

Wassilieff ${ }^{2}$ ) untersuchte 7 tägige Keimpflanzen, die in einem Raume unseres Instituts bei $22-23^{\circ}$ C. in Sand gezogen waren und sich bei dieser relativ hohen Temperatur rasch entwickelt hatten. Aus den Cotyledonen dieser Pflänzchen konnte Wassilieff Leucin, Tyrosin, Arginin und Histidin darstellen; die übrigen Pflanzenteile lieferten ihm ein Amino-

1) Die analytischen Belege zu dieser Bestimmung sind weiter oben schon mitgeteilt worden.

2) loc. cit. 
säurengemenge, in welchem Leucin, Aminovaleriansäure und Phenylanalin sich vorzufinden schienen. Die von Wassilieff ausgeführten Quantitätsbestimmungen lieferten folgende Zahlen:

Die Keimpflanzentrockensubstanz enthielt:

$\begin{array}{ll}\text { Gesamtstickstoff } & 8,43 \%, \\ \text { Proteinstoffe } & 21,48 \% \text { mit } 3,58 \% \mathrm{~N} \\ \text { Asparagin } & 12,78 \%>2,71 \%>\end{array}$

Wir haben nun noch in Pflänzchen, welche ungefähr den gleichen Entwicklungsgrad erreicht hatten, wie die von Wassilieff untersuchten, den Arginingehalt in der früher beschriebenen Weise bestimmt und fanden denselben gleich $0,13 \%$ der Keimpflanzentrockensubstanz. Wir erhielten hier also weniger Arginin, als aus den 4 tägigen Pflänzchen. Dies kann im Zusammenhang mit der starken Asparaginbildung stehen, die bei der Weiterentwicklung der Pflänzchen eingetreten war. Doch muß es für möglich erklärt werden, daß diese Pflänzchen schon im Alter von 4 Tagen weniger Arginin enthielten, als die 4 tägigen Pflänzchen, in denen $0,28 \%$ Arginin gefunden wurde; denn es liegt auf der Hand, daß ein dem Abbau unterliegendes Eiweißzersetzungsprodukt sich in Pflänzchen, die einen bestimmten Grad der Entwicklung erreicht haben, in wechselnder Menge vorfinden kann.

Über den Gehalt der Keimpflanzen der I. Periode an Leucin und andern Aminosäuren lassen sich bestimmte quantitative Angaben nicht machen; doch war dieser Gehalt ohne Zweifel ein ziemlich beträchtlicher. Aus den Cotyledonen der 7 tägigen Keimpflanzen erhielt Wa ssilieff bei nur einmaligem Extrahieren der zerriebenen Cotyledonen mit 92\% igem Weingeist ungefähr 0,5\% Aminosäuren (gewogen als Rohprodukt); fast die gleiche Ausbeute erhielt E. Schulze bei gleichem Verfahren aus den Cotyledonen der von ihm untersuchten 6 tägigen Pflänzchen. Allem Anschein nach war Leucin der Hauptbestandteil dies Rohprodukts; denn das letztere lieferte beim Umkrystallisieren ohne Schwierigkeit ein nahezu reines Leucinpräparat. Tyrosin fand sich stets in weit geringerer Menge vor als Leucin. Daß in einwöchentlichen Keimpflanzen von Lupinus albus Leucin zuweilen in sehr beträchtlicher Menge 
vorkommt, geht auch aus den von Belzung gemachten Angaben hervor; denn derselbe vermochte aus dem frischen Saft solcher Keimlinge mit Leichtigkeit die genannte Aminosäure abzuscheiden. Doch haben wir bei den von uns untersuchten Keimpflanzen gleichen Alters nicht das Gleiche beobachten können.

Als ein für die Autodigestionsversuche $\mathrm{zu}$ verwendendes Material wurden schließlich noch zweitägige Keimpflanzen untersucht. Die Analyse derselhen lieferte folgende Resultate:

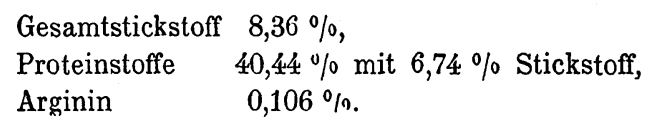

Vorstehende Prozentzahlen beziehen sich jedoch auf die entfettete Trockensubstanz. Auf die fetthaltige Trockensubstanz bezogen, $\left.{ }^{1}\right)$ würden sie etwas niedriger ausfallen; der Arginingehalt z. B. würde dann $0,10 \%$, der Proteingehalt $37,7 \%$ betragen.

Diese zweitägigen Keimpflanzen enthielten ohne Zweifel krystallinische Eiweißzersetzungsprodukte erst in sehr kleiner Quantität. Bei dem Versuche, aus ihnen nach dem weiter unten in dem Abschnitt $D$ beschriebenen Verfahren Leucin und Tyrosin darzustellen, erhielten wir nur eine äußerst geringe Menge dieser Aminosäuren. Wir versuchten sodann noch, aus frischen zweitägigen Keimpflanzen Tyrosin zu gewinnen, indem wir die zerriebenen Pflänzchen mit Wasser kochten, den filtrierten Auszug von den durch Bleiessig fällbaren Substanzen befreiten und sodann mit Mercurinitrat versetzten (zur Abstumpfung der sauren Reaktion der Flüssigkeit wurde dann noch etwas Soda zugefügt). Bei Zerlegung des erst nach mehrtägigem Stehen abfiltrierten Mercurinitratniederschlags durch Schwefelwasserstoff wurde eine Flüssigkeit erhalten, welche zwar beim Erwärmen mit Millonschem Reagens schwache Rötung gab; doch konnten wir aus dieser Flüssigkeit nur Krystalle von Asparagin, aber kein Tyrosin zur Abscheidung bringen.

Diese Wahrnehmungen erklären sich aus der Tatsache, daß in den zweitägigen Keimpflanzen noch nicht viel Eiweißsubstanz zerfallen war. Vergleicht man die bei der Analyse

1) Die 2 tägigen Keimpflanzen enthielten $6,8 \%$ Fett. 
dieser Pflanzen erhaltenen Resultate mit denjenigen, die sich bei der Analyse der ungekeimten Samen ergaben, so kommt man zu der Schlußfolgerung, daß die während zweitägiger Keimung zerfallene Eiweißmenge ungefähr $4 \%$ der Pflanzentrockensubstanz betrug. Aus diesem Quantum kann sich nicht eine große Menge von krystallinischen Eiweißzersetzungsprodukten gebildet haben. W'ir wollen von dem letzteren speziell das Tyrosin ins Auge fassen. In der von F. N. Schulzi) vor kurzem publizierten Zusammenstellung der über die Tyrosinausbeute aus verschiedenen Eiweißstoffen gemachten Angaben findet man nur bei der Seide Zahlen, welche $5 \%$ erreichen oder noch darüber hinausgehen; alle übrigen Zahlen sind niedriger. Nehmen wir nun an, daß bei der Spaltung der Eiweißsubstanz in den zweitägigen Keimpflanzen 5\% Tyrosin entstanden sind, ${ }^{2}$ ) so würden diese Pflanzen nicht mehr als $0,2 \%$ Tyrosin enthalten können. Da nun aber anzunehmen ist, daß erstens jene $4 \%$ Eiweißsubstanz nicht vollständig in krystallinische Produkte zerfallen waren und daß zweitens das dabei entstandene Tyrosin dem Abbau verfiel, so muß der Tyrosingehalt der zweitägigen Pflänzchen noch niedriger gewesen sein, falls nicht etwa die Eiweißsubstanz bei der Spaltung in den Keimpflanzen Tyrosin in weit höherem Maße geliefert hat, als bei der Spaltung außerhalb des Organismus. Zieht man alle diese Umstände in Betracht, so wird man sich nicht darüber wundern können, daß wir aus den zweitägigen Pflänzchen Tyrosin kaum darzustellen vermochten; es erklärt sich auch, da $B$ die aus denselben abgeschiedene Argininmenge nur $0,1 \%$ der Pflanzentrockensubstanz betrug.

Etwas überraschend ist nun die relativ hohe Ausbeute an Tyrosin, welche R. Bertel ${ }^{3}$ ) aus den Wurzeln zweitägiger Keimpllanzen von Lupinus albus erhielt. Er macht darüber

1) F. N. Schulz, Die Größe des Eiweißmoleküls (Jena bei Fischer, 1903), S. 88.

2) Bei Zersetzung eines aus Lupinensamen dargestellten Eiweißpräparats durch Salzsäure oder durch Barytwasser in unserem Laboratorium wurde nur ca. 2,5\% Tyrosin erhalten.

3) loc. cit. 
folgende Angaben: Die bis zu einer Länge von $4 \mathrm{~cm}$ entwickelten Wurzeln wurden von den Pflänzchen abgetrennt, zerrieben und sodann mit Wasser ausgekocht. Der mit Hilfe eines Seihtuchs vom Ungelösten getrennte Auszug lieferte, nachdem er auf $1 / 4$ seines Volumens eingedunstet worden war, beim Erkalten einen weißen Niederschlag von Tyrosin. Dieser Niederschlag bestand aus Sphäriten, war löslich in kochendem Wasser und in Alkalien, löste sich aber nur schwierig in Säuren, mit Millonschem Reagens gab er eine rote Lösung. Die frischen Wurzeln lieferten ungefähr $1 \%$ von diesem Produkt. Da nun nach einer von uns ausgeführten Bestimmung solche Wurzeln nur $6 \frac{1 / 2}{2} \%$ Trockensubstanz enthalten, so würde die von Bertel erhaltene Tyrosinausbeute ungefähr $1,5 \%$ der Pflanzentrockensubstanz betragen haben.

Zwei Versuche, die wir unter Befolgung der von Bertel gegebenen Vorschrift mit den bis zu einer Länge von $4 \mathrm{~cm}$ entwickelten Wurzeln zweitägiger Keimpflanzen von Lupinus albus ausführten, gaben ein anderes Resultat. Allerdings lieferte der im Wasserbade auf $1 / 4$ des ursprünglichen Volumens eingeengte wässerige Auszug beim Erkalten einen weißen Niederschlag, welcher im Verhalten gegen Lösungsmittel den Angaben Bertels entsprach, stickstoffhaltig war und beim Erwärmen mit Millonschen Reagens eine rote Lösung gab; aber die Substanz, aus welcher der Niederschlag bestand, verhielt sich im übrigen nicht wie Tyrosin. Diese Substanz gab weder die Piriasche noch die vor kurzem vou Mörner ${ }^{1}$ ) beschriebene Reaktion auf Tyrosin; auch lieferte sie beim Erhitzen mit Kupferhydroxyd und Wasser eine ungefärbte Flüssigkeit, ${ }^{2}$ ) während Tyrosin bei gleicher Behandlung eine blaue Lösung gibt. Krystallinische Beschaffenheit konnte bei dieser Substanz nicht konstatiert werden. Worin der Grund dafür liegt, daß wir zu einem anderen Re-

1) Diese Zeitschrift, Bd. XXXVII, S. 86.

2) Die vom Kupferhydroxydniederschlag abfiltrierte Flüssigkeit gab beim Verdunsten einen kleinen Rückstand, der mit Millonschem Reagens Rotfärbung gab; möglich ist, daß hier eine Spur von Tyrosin vorhanden war. 
sultate gelangten, als Bertel, das ist eine Frage, deren Diskussion wir noch verschieben wollen.

Eine weiße Ausscheidung, wie wir sie aus dem wässerigen Extrakt aus den Wurzeln erhielten, lieferte auch ein wässeriger Auszug aus den übrigen Pflanzenteilen. Es wird vielleicht von Interesse sein, dieselbe noch einer Untersuchung zu unterwerfen.

\section{Etiolierte 18tägige Keimpflanzen.}

Aus den Axenorganen 2-21/2 wöchiger etiolierter Keimpflanzen von Lupinus albus hat E. Schulze früher Aminovaleriansäure und Phenylalanin dargestellt. Im übrigen sind solche Pflänzchen noch nicht untersucht worden. Es trat also an uns die Aufgabe heran, sie einer eingehenden Untersuchung zu unterwerfen. Die Bearbeitung dieser Aufgabe konnte jedoch von uns noch nicht vollständig durchgeführt werden, wie aus den weiter unten folgenden Mitteilungen zu ersehen ist.

Die zur Untersuchung verwendeten Pflänzchen waren in einem verdunkelten Raume bei einer Temperatur von 20-220 gewachsen uud hatten eine bedeutende Größe erlangt (Länge des hypocotylen Glieds 20-22 cm). Sie waren außerordentlich reich an Asparagin. Die Analyse gab folgende Resultate:

Die Keimpflanzentrockensubstanz enthielt:

\begin{tabular}{|c|c|}
\hline Gesamtstickstoff & $10,08 \%$ \\
\hline Proteinstoffe & $10,38 \%$ mit $1,73 \%$ \\
\hline Asparagin & $25,64 \% \diamond 5,44 \%$ \\
\hline Arginin & $0,14 \%>0,045 \%$ \\
\hline
\end{tabular}

Diese Pflänzchen enthielten also noch ein wenig Arginin. Auch in einer anderen Kultur etiolierter Keimpflanzen von Lupinus albus, die unter den gleichen Bedingungen, jedoch unter Verwendung eines anderen Samenmusters dargestellt waren, ließ sich Arginin gewinnen; seine Quantität betrug hier 0,12\% der Pflanzentrockensubstanz. ${ }^{2}$ ) Das Arginin wurde zunächst in das Nitrat, dann in die Verbindung mit Kupfernitrat übergeführt. Diese Verbindung krystallisierte in der

1) $339,2 \mathrm{~g}$ Trockensubstanz gaben $0,784 \mathrm{~g}$ Argininkupfernitrat = 0,4625 g Arginin.

2) $1000 \mathrm{~g}$ Trockensubstanz gaben $1,968 \mathrm{~g}$ Kupferargininnitrat $=$ 1,161 g Arginin. 
charakteristischen Form und schmolz bei 113-114?. Die Bestimmung des Kupfers in einem durch Trocknen bei 80 , später bei $100^{\circ}$ vom Krystallwasser befreiten Präparat gab folgende Resultate:

1. 0,2635 g Substanz gaben $0,0385 \mathrm{~g} \mathrm{CuO}$.

2. 0,2625 \& " * 0,0385 " $\mathrm{CuO}$.

Berechnet für $\left(\mathrm{C}_{6} \mathrm{H}_{14} \mathrm{~N}_{4} \mathrm{O}_{2}\right)_{2} \mathrm{Cu}\left(\mathrm{NO}_{3}\right)_{2}$ : Gefunden:
$\mathrm{Cu} \quad 11,89$
1. 11,68
2. 11,72

Neben Arginin erhielten wir bei Anwendung des früher angegebenen Trennungsverfahrens auch etwas Histidin, doch war die Ausbeute noch geringer als die Ausbeute an Arginln. Da das Histidin nicht ganz rein zu sein schien, so fällten wir es noch einmal durch Phosphorwolframsäure aus und versetzten dann die bei Zerlegung des Niederschlags erhaltene Lösung mit Quecksilberchlorid. Der durch dieses Reagens hervorgebrachte Niederschlag lieferte bei der Zerlegung durch Schwefelwasserstoff ein Produkt, welches in kleinen glänzenden Tafeln krystallisierte. Diese Krystalle stimmten im Aussehen mit dem Monochlorhydrat des Histidins überein und besaßen einen der Formel dieser Verbindung $=\mathrm{C}_{6} \mathrm{H}_{9} \mathrm{~N}_{3} \mathrm{O}_{2}, \mathrm{HCl}+\mathrm{H}_{2} \mathrm{O}$ entsprechenden Chlorgehalt, wie folgende Angaben beweisen:

$0,1670 \mathrm{~g}$ Substanz gaben $0,1125 \mathrm{~g}$ Chlorsilber $=0,02832 \mathrm{~g}$ oder $16,91 \% \mathrm{Cl}$ (die Theorie verlangt $16,90 \% \mathrm{Cl}$ ).

Das aus dem Filtrat vom Chlorsilber durch Ausfällung mittels Silbernitrat und Ammoniak dargestellte Silberhistidin besaß einen der Formel $\mathrm{C}_{6} \mathrm{H}_{7} \mathrm{~N}_{3} \mathrm{O}_{2} \mathrm{Ag}_{2}+\mathrm{H}_{2} \mathrm{O}$ entsprechenden Silbergehalt:

$0,2660 \mathrm{~g}$ Substanz (bei $100^{\circ}$ getrocknet) gaben 0,1485 $\mathrm{g} \mathrm{Ag}=55,83 \%$ (die Theorie verlangt $55,77 \% \mathrm{Ag}$ ).

Diese Versuchsergebnisse beweisen, daß reines Histidinchlorid vorlag.

Das Arginin und das Hisidin wurden, wie aus den weiter oben gemachten Angaben hervorgeht, aus dem durch Silberlösung und Barytwasser hervorgebrachten Niederschlage dargestellt. Die im Filtrat von diesem Niederschlage noch enthaltenen Basen, unter denen vermutlich auch Lysin sich vorfand, haben wir bis jetzt noch nicht untersucht. Die Untersuchung 
dieses Basengemenges gehört zu den in der Einleitung erwähnten Aufgaben, die wir uns gestellt haben; doch wird sich diese Aufgabe erst nach Beschaffung einer größeren Materialmenge erfolgreich bearbeiten lassen.

Die in den etiolierten Keimpflanzen von Lupinus albus sich vorfindenden Aminosäuren sind, wie oben schon erwähnt ist, im hiesigen Laboratorium früher schon untersucht worden. Aus den Axenorganen solcher Pflänzchen ließen sich Aminovaleriansäure und Phenylalanin darstellen; Leucin ließ sich daraus nicht gewinnen, fehlte aber wohl nicht vollständig und fand sich wahrscheinlich in etwas größerer Menge in den Cotyledonen der genannten Pflänzchen vor. Auch aus den von uns untersuchten 18 tägigen Pflänzchen konnten leicht solche Aminosäuren dargestellt werden, indem man die trockenen Pflänzchen mit $92 \%$ \%igem .Weingeist auskochte und den Auszug nach früher oft beschriebenem Verfahren verarbeitete; die Ausbeute betrug, bei zweimaligem Auskochen mit Weingeist, etwas mehr als 1\% des Ausgangsmaterials. Das Rohprodukt wurde zunächst durch Umkrystallisieren aus einem Gemisch von Weingeist und Ammoniakflüssigkeit gereinigt; dann wurde daraus Phenylalanin dargestellt und zwar teils durch Kochen des Aminosäurengemenges mit Kupferoxydhydrat, teils durch Fällung mit Phosphorwolframsäure in der von E. Schulze und E. Winterstein beschriebenen Weise (das Phenylalanin wurde durch seine Reaktionen, sein spezifisches Drehungsvermögen und eine Kupferbestimmung im Kupfersalz identifiziert). ${ }^{1}$ ) Das nach Abscheidung des Phenylalanins übrig gebliebene Aminosäurengemenge bildete nach mehrmaligem Umkrystallisieren aus Weingeist und Ammoniak eine aus farblosen, glänzenden Blättchen bestehende Krystallmasse. Beim Erhitzen im Glasröhrchen verflüchtigte sich dieses Produkt vollständig unter Bildung eines weißen Sublimats. Beim Erhitzen seiner wässerigen Lösung mit Kupferacetat entstand keine Ausscheidung, das Produkt zeigte also das Verhalten der Aminovaleriansäure.

Daß es trotzdem auch Leucin einschloß, war nach den Resultaten der früher ausgeführten Untersuchungen anzunehmen,

1). Diese Zeitschrift, Bd. XXXV, S. 210. 
dies wird auch durch das Ergebnis bewiesen, welches bei Untersuchung eines aus jenem Produkt dargestellten Kupfersalzes erhalten wurde. Der Kupfergehalt dieses Salzes betrug 20,92 \% und lag also zwischen dem Kupfergehalt des Leucinkupfers $(19,55 \%)$ und demjenigen des aminovaleriansauren Kupfers $(21,42 \%)$. Wahrscheinlich enthielt aber jenes Aminosäurengemenge weit mehr Aminovaleriansäure als Leucin. Wäre es anders gewesen, so würde man, da Leucin schwerer löslich ist als Aminovaleriansäure, bei wiederholtem Umkrystallisieren ein an Leucin sehr reiches, an Aminovaleriansäure armes Präparat erhalten haben; gerade das Entgegengesetzte war aber der Fall. Tyrosin konnte weder aus dem von uns untersuchten Aminosäurengemenge, noch aus den früher im hiesigen Laboratorium untersuchten, mehrwöchigen Keimpflanzen der gleichen Lupinusart isoliert werden, fehlte aber vermutlich darin nicht vollständig.

Es muß als wünschenswert bezeichnet werden, daß auf die aus den Keimpflanzen darstellbaren Aminosäuren noch Emil Fischers Trennungsverfahren (fraktion. Destillation der Ester im luftleeren Raum) angewendet wird. Wir hoffen, diese Aufgabe demnächst noch in Angriff nehmen zu können.

Nach den im vorigen gemachten Mitteilungen enthalten die 18 tägigen etiolierten Keimpflanzen von Lupinus albus Asparagin, Leucin, Aminovaleriansäure, Phenylalanin, Arginin und Histidin; auch Ammoniak war in kleiner Menge vorhanden. Es kann aber keinem Zweifel unterliegen, daß neben diesen Stoffen noch andere, nicht proteinartige Stickstoffverbindungen sich vorfanden. Dafür sprechen unter anderem folgende Tatsachen. Wenn man vom Gesamtstickstoff $\left(10,68^{\circ} / 0\right)$ den nach Stutzers Verfahren ermittelten «Proteinstickstoff» $(1,73 \%)$ abzieht, so bleibt ein Rest von 8,35\%. Subtrahiert man von diesem Rest die auf Asparagin fallende Stickstoffmenge $(5,44 \%)$, so bleiben $2,91 \%$ übrig (alle diese Prozentzahlen beziehen sich auf die Keimpflanzentrockensubstanz). Wie viel Stickstoff den oben genannten Aminosäuren und Hexonbasen und dem Ammoniak angehört, läßt sich nicht genau angeben; wahrscheinlich aber wird der Be- 
trag 0,6-0,7\% der Pflanzentrockensubstanz kaum übersteigen. Gesetzt aber auch, daß derselbe noch etwas größer ist und $0,9 \%$ ausmacht, so würden doch immer noch $2 \%(=20 \%$ des Gesamtstickstoffs) auf andere Verbindungen fallen. Daß unter diesen Verbindungen auch in Wasser lösliche Basen sich vorfanden, zeigte auch der folgende Versuch: Ein durch Erhitzen mit Kupferoxydhydrat nach Stutzers Verfahren von den Proteinstoffen befreites wässeriges Extrakt aus den fein zerriebenen Keimpflanzen wurde angesäuert und mit Phosphorwolframsäure versetzt, der Niederschlag nach dem Abfiltrieren und Auswaschen durch Baryumhydroxyd zerlegt, die dabei erhaltene Basenlösung vom Ammoniak befreit und sodann zur Stickstoffbestimmung nach Kjeldahls Methode verwendet. Die darin vorgefundene Stickstoffmenge betrug 0,74\% der Pflanzentrockensubstanz. Subtrahiert man davon die auf Arginin und Histidin fallende Stickstoffmenge, welche höchstens $0,1 \%$ betragen kann, so bleiben noch $0,64 \%$ übrig. Welchen Basen dieser Rest angehört, das werden wir bei Fortführung unserer Arbeit festzustellen suchen.

Welchen Verbindungen die nach Abzug jener $0,64 \%$ von den oben aufgeführten Restbetrage $\left(2,0^{\circ} / 0\right)$ noch übrig bleibende Stickstoffmenge $(1,36 \%)$ angehört, darüber vermögen wir zur Zeit keine Angaben zu machen. Es scheint fast, daß die Keimpflanzen noch gewisse, in Wasser leicht lösliche Produkte des Eiweißumsatzes, deren Natur bis jetzt unbekannt ist, in beträchtlicher Menge enthalten. Vielleicht wird es uns bei Fortführung unserer Untersuchungen möglich sein, auch darüber Aufschluß zu gewinnen.

Vergleichung der 18 tägigen, etiolierten Keimpflanzen mit den Pflänzchen der I. Entwicklungsperiode.

Die 18tägigen etiolierten Keimpflanzen sind weit ärmer an Proteinstoffen, dagegen weit reicher an Asparagin, auch reicher an Aminovaleriansäure und an Phenylalanin, als die Keimpflanzen der I. Periode. Tyrosin findet sich in ihnen zweifellos in geringerer Menge, als in den zuletztgenannten 
Pflänzchen; ihr Arginingehalt wurde nur halb so groß gefunden, als derjenige der 4tägigen Keimpflanzen. Daraus ergibt sich, daß Tyrosin und Arginin im Stoffwechsel der Pflänzchen dem Verbrauche unterliegen. Der Unterschied im Leucingehalt der Pflänzchen verschiedenen Alters läßt sich nicht in Zahlen ausdrücken, da wir kein Verfahren zur quantitativen Bestimmung des Leucins besitzen. Es ist aber sehr wahrscheinlich, daß die 18 tägigen etiolierten Pflänzchen weniger Leucin enthalten, als die 6-7tägigen Keimpflanzen; denn aus den letzteren ließ sich leicht reines Leucin in beträchtlicher Quantität gewinnen, während die 18tägigen, etiolierten Pfänzchen ein Aminosäurengemenge lieferten, welches größtenteils aus Aminovaleriansäure und Phenylalanin bestand. Gesetzt aber auch, daß der Leucingehalt der genannten beiden Objekte der gleiche wäre, so würde man doch einen Verbrauch von Leucin im Stoffwechsel der Pflänzchen anzunehmen haben. Andernfalls würde man ja die höchst unwahrscheinliche Annahme machen müssen, dảß die nach dem 6 ten oder 7 ten Tage der Keimung noch erfolgte Spaltung von Eiweißstoffen ohne Bildung von Leucin vor sich gegangen wäre. Übrigens müßte ja auch dann, wenn kein Leucin mehr gebildet worden wäre, die durch den Atmungsprozeß bewirkte Abnahme der Keimpflanzentrockensubstanz ein Ansteigen des Prozentgehalts dieser Trockensubstanz an Leucin zur Folge gehabt haben. Man hat somit anzunehmen, daß der Stoffwechsel unserer Pflänzchen mit einem Verbrauch von Tyrosin, Leucin und Arginin verbunden war.

\section{Autodigestionsversuche mit 2- und 3 tägigen Keimpflanzen.}

Da von Butkewitsch (loc. cit.) schon mit Sicherheit nachgewiesen worden ist, daß bei der Autodigestion von Lupinuskeimpflanzen Leucin und Tyrosin sich bilden, so haben wir bei den Autodigestionsversuchen unsere Aufmerksamkeit zunächst auf das Arginin, daneben auch auf die andern Hexonbasen, gerichtet. Die meisten dieser Versuche führten wir in der von Butkewitsch beschriebenen Art und Weise aus. Als Material dienten 2tägige Keimpflanzen von 
Lupinus albus, welche von den Schalen befreit, fein zerrieben und mit Äther behandelt worden waren; nach längerem Verweilen unter dem Äther wurden sie durch Filtration von der fetthaltigen Lösung getrennt und sodann im Exsiccator über konzentrierter Schwefelsäure getrocknet. Die Analyse gab für die fettfreie Trockensubstanz folgende Resultate:

$\begin{array}{ll}\text { Gesamtstickstoff } & 8,36 \% \\ \text { Stickstoff in Proteinstoffen } & 6,74 \%\end{array}$

Verarbeitet in der früher beschriebenen Weise lieferte dieses Ausgangsmaterial 0,106\% Arginin und 0,045\% Histidin. ${ }^{1}$ ) Wir haben auch noch die Stickstoffmenge in dem durch Silberlösung und Barytwasser erzeugten Niederschlage, welcher das Arginin und das Histidin neben einer kleinen Menge anderer Substanzen einschloß, bestimmt; diese Stickstoffmenge betrug $0,088 \%$ der fettfreien Trockensubstanz. ${ }^{2}$ ) Die von jenem Niederschlage abfiltrierte Flüssigkeit, welche das Lysin und andere Basen, z. B. Cholin, enthalten mußte, wurde durch Schwefelsäure vom Baryt befreit, sodann mit Phosphorwolframsäure versetzt, der durch dieses Reagens hervorgebrachte Niederschlag durch Barytwasser zersetzt, in der dabei erhaltenen Basenlösung die Stickstoffmenge bestimmt. Letztere betrug 0,114\% der Trockensubstanz des Ausgangsmaterials. ${ }^{3}$ )

Von diesem Material wurden nun $50 \mathrm{~g} \quad(=44,85 \mathrm{~g}$ wasserfrei) mit $250 \mathrm{ccm}$ Wasser unter Zusatz von etwas zerriebenem Thymol und etwas Toluol in einen vorher sterilisierten und mit Wattepfropf versehenen Glaskolben gebracht und hierauf 7 Tage lang im Brutschrank auf $35-40^{\circ}$ erwärmt.

1) Analytische Belege: $143,52 \mathrm{~g}$ Trockensubstanz gaben $0,258 \mathrm{~g}$ Argininkupfernitrat $=0,1525$ Arginin und 0,144 $\mathrm{g}$ Histidinsilber $=0,0644 \mathrm{~g}$ Histidin (das Histidinsilber war nicht völlig rein).

2) Angewendet $35,88 \mathrm{~g}$ Trockensubstanz. Volumen der argininund histidinhaltigen Lösung $=50 \mathrm{ccm}$. Je $25 \mathrm{ccm}$ dieser Lösung gaben nach Kjeldahls Verfahren a) 0,0161 g N; b) 0,0153 g N (Mittel 0,0157 g N).

3) Angewendet $143,520 \mathrm{~g}$ Trockensubstanz. Volumen der lysinhaltigen Lösung $=100 \mathrm{ccm}$. Je $25 \mathrm{ccm}$ davon gaben a) $0,04088 \mathrm{~g} \mathrm{~N}$; b) $0,04118 \mathrm{~g} \mathrm{~N}$. 
Dann wurde die Flüssigkeit vom Ungelösten abfiltriert, ${ }^{1}$ ) das mit dem Waschwasser vereinigte Filtrat von den durch Tannin und durch Bleiessig fällbaren Substanzen befreit, sodann mit Schwefelsäure stark angesäuert und, nach nochmaliger Filtration, mit Phosphorwolframsäure versetzt. Aus der Lösung, die bei Zerlegung des Phosphorwolframsäureniederschlags durch Baryumhydroxyd erhalten wurde, fällten wir Arginin und Histidin zusammen durch Silbernitrat und Barytwasser aus und bestimmten in dem sorgfältig ausgewaschenen Niederschlage die Stickstoffmenge; letztere betrug 0,262 \% der Trockensubstanz des Ausgangsmaterials. ${ }^{2}$ ) Die in den Silberniederschlag eingehende Stickstoffmenge war also während der Autodigestion von 0,088 auf $0,262 \%, d$. h. auf das Dreifache gestiegen.

Für einen zweiten Versuch wurden $200 \mathrm{~g}$ des Ausgangsmaterials ( $=179,4 \mathrm{~g}$ wasserfrei), verteilt in 4 Kolben, verwendet. Die Autodigestion geschah unter den gleichen Bedingungen, wie im ersten Versuch, wurde aber länger (14 Tage lang) fortgesetzt. Dann wurde der Inhalt der 4 Kolben auf ein Filter gebracht. Das mit dem Waschwasser vereinigte Filtrat verarbeiteten wir in der bei Beschreibung des ersten Versuchs angegebenen Weise, nur mit dem Unterschiede, daß wir in diesem Falle Arginin und Histidin getrennt ausfällten und in Substanz darstellten. Wir erhielten dabei folgende Resultate:

$179,4 \mathrm{~g}$ des Ausgangsmaterials (wasserfrei in Rechnung gestellt) lieferten nach der Autodigestion

$1,595 \mathrm{~g}$ Argininkupfernitrat $=0,9426 \mathrm{~g}$ oder $0,525 \%$ Arginin und $0,4285 \mathrm{~g}$ Histidinsilber $=0,1915 \mathrm{~g}$ oder $0,107 \%$ Histidin.

Das in diesem Versuche erhaltene Argininkupfernitrat besaß nach einmaligem Umkrystallisieren aus Wasser einen

1) Nach Beendigung des Erhitzens im Brutschrank wurde bei den hier beschriebenen Autodigestionsversuchen fast ausnahmslos der Inhalt der Kolben bis zum Sieden erhitzt.

2) Analytische Belege: angewendet: $44,85 \mathrm{~g}$ Trockensubstanz. Volumen der arginin- und histidinhaltigen Lösung $=50 \mathrm{ccm}$. Je $25 \mathrm{ccm}$ davon gaben a) $0,05870 \mathrm{~g} \mathrm{~N}$; b) $0,0590 \mathrm{~g} \mathrm{~N}$. 
Schmelzpunkt von $112-114^{0}$. Eine in dem entwässerten Salz ausgeführte Kupferbestimmung gab folgendes Resultat:

$0,2780 \mathrm{~g}$ der vom Krystallwasser befreiten Verbindung gaben $0,0410 \mathrm{~g} \mathrm{CuO}$ $=11,77 \% \mathrm{Cu}$. (Die Theorie verlangt $11,89 \% \mathrm{Cu}$.)

Vergleicht man die in diesem Versuche erhaltene Argininmenge mit derjenigen, welche aus dem Ausgangsmaterial gewonnen werden konnte, so zeigt sich, daß die Argininmenge während der Autodigestion auf das Fünffache gestiegen ist. Gleichzeitig hat sich auch die Quantität des Histidins vermehrt, und zwar ist sie auf das $21 / 2$ fache gestiegen.

Das Filtrat von dem Argininsilberniederschage wurde durch Zusatz von Salzsäure vom Silber, durch Zusatz von Schwefelsäure vom Baryt befreit und sodann mit Phosphorwolframsäure versetzt. Den durch dieses Reagens hervorgebrachten Niederschlag zerlegten wir durch Baryumhydroxyd und bestimmten in der dabei erhaltenen Lösung, in welcher auch das Lysin sich vorfinden mußte, die Stickstoffmenge. Letztere betrug $0,174 \%$ der Trockensubstanz des Ausgangsmaterials; sie war also um $0,06 \%$ höher als die in gleicher Weise für das ursprüngliche Material gefundene Zahl. Dieses Resultat macht es sehr wahrscheinlich, daß während der Autodigestion auch die Quantität des Lysins sich vermehrt hatte.

Aus den im vorigen mitgeteilten Versuchsergebnissen ist zu ersehen, daß die Autodigestion der Keimpflanzen eine Bildung von Arginin und Histidin, wahrscheinlich auch von Lysin, zur Folge hatte, eine Erscheinung, die man auf die Wirksamkeit des proteolytischen Enzyms der Keimpflanzen zurückzuführen hat. Doch hat die Quantität der Hexonbasen keine sehr bedeutende Zunahme erfahren, trotz der langen Dauer der Autodigestion. Dies war freilich nach den von Butkewitsch (loc. cit.) gemachten Beobachtungen von vornherein zu erwarten, denn der Genannte fand bei Autodigestionsversuchen mit Lupinenkeimlingen, ${ }^{1}$ ) daß die dem Phosphorwolframsäurenniederschlag angehörendeStickstoffmenge während der Versuche nicht sehr stark gestiegen war. Da in den gleichen

1) Im folgenden reproduzieren wir einen Teil der von Butkewitsch mitgeteilten Resultate; unter a führen wir die im Ausgangs- 
Versuchen die im Filtrat vom Phosphorwolframsäureniederschlag enthaltene Stickstoffmenge stark gestiegen war, so kann man aus jener Tatsache noch nicht auf eine schwache Wirksamkeit des proteolytischen Enzyms schließen, immerhin kann man die Frage stellen, warum auch bei langer Fortsetzung der Autodigestion die Eiweißmenge sich niemals so stark verringerte, wie in den lebenden Keimpflanzen bei 12 bis 15 tägiger Dauer der Vegetation unter Lichtabschluß.

Am wahrscheinlichsten ist es wohl, daß im Beginn der Keimung ein großes Quantum des proteolytischen Enzyms noch nicht vorhanden war und daß dieses Enzym sich erst in dem Maße bildete, wie die Keimpflanzen seiner bedurften ${ }^{1}$ ) Vielleicht sind aber auch noch andere Umstände von Einfluß. So bildet sich z. B. im Stoffwechsel der lebenden Pflänzchen vielleicht irgend eine Substanz, z. B. eine Säure, deren Vorhandensein die Wirkung des Enzyms unterstützt; auch ist es wahrscheinlich, daß in den Autodigestionsversuchen der Zusatz der Antiseptica die Wirkung des Enzyms abschwächte.

Die im letzten Satze geäußerten Anschauungen veranlaßten uns, noch einen Autodigestionsversuch mit zerriebenen und entfetteten Keimpflanzen anzustellen, in welchem als Antiseptikum Chloroform, daneben eine kleine Quantität von Citronensäure zugesetzt wurde. Dieser Versuch, für welchen $50 \mathrm{~g}$ lufttrockene Substanz (=43,94 $\mathrm{g}$ wasserfrei), $\left.{ }^{2}\right) 0,25 \mathrm{~g}$ Citronensäure und $250 \mathrm{ccm}$ Wasser verwendet wurden, dauerte 7 Tage (Temperatur 35-40 ), nach Beendigung des Erwärmens wurde die Flüssigkeit ebenso wie bei den andern Versuchen

material, unter b die nach 12 tägiger Autodigestion erhaltenen Zahlen auf.

\begin{tabular}{|c|c|c|c|}
\hline \multicolumn{2}{|c|}{$\begin{array}{l}\text { Keimpflanzen von } \\
\text { Lupinus angustifolius }\end{array}$} & \multicolumn{2}{|c|}{$\begin{array}{c}\text { Cotyledonen } 6 \text { tägiger } \\
\text { Keimpflanzen }\end{array}$} \\
\hline 2 tägig & 4 tägig & & \\
\hline b) & b) & a) & b) \\
\hline 354,8 & 5,3 & 6 & 5 \\
\hline $30 \quad 0,4$ & 0,48 & 0,93 & 1,17 \\
\hline$, 42 \quad 1,81$ & $0,73 \quad 2,18$ & 3,42 & 4,80 \\
\hline
\end{tabular}

Proteinstickstoff (nach Statzer) . . . . . $6,35 \quad 4,82 \quad 6,33 \quad 4,72 \quad 6,77 \quad 5,15$

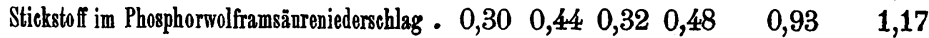

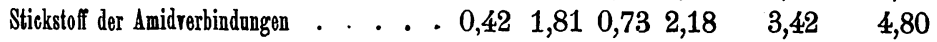

1) M. vgl. W. Pfeffer, Die regulatorische Bildung von Diastase, Berichte der sächsischen Akademie. d. Wissenschaften, 7. Dezember 1896.

2) Die für diese und die folgenden Versuche benutzten zweitägigen Keimpflanzen entstammten einer andern Kultur, als die früher verwendeten. 
verarbeitet. Die Stickstoffmenge, welche in dem durch Silbernitrat und Barytwasser hervorgebrachten Niederschlage vorgefunden wurde, betrug 0,276\% der Keimpflanzentrocken$\left.\operatorname{substanz} ;^{1}\right)$ sie war also nur um einen unwesentlichen Betrag höher, als die im ersten Autodigestionsversuche in gleicher Weise erhaltene Stickstoffquantität $(0,262 \%)$. Immerhin scheint der Säurezusatz günstig gewirkt zu haben.

Wir hielten es für angezeigt, auch noch Autodigestionsversuche mit frischen Keimpflanzen zu machen, um zu prüfen, $\mathrm{ob}$ in diesem Falle die Verhältnisse für die Bildung von Arginin günstiger waren. Die für diese Versuche verwendeten Keimpflanzen waren etwa 3 Tage alt und demgemäß in der Entwicklung weiter fortgeschritten, als die für die andern Versuche benutzten Pflänzchen. Sie wurden zerrieben und sodann unter Zusatz von Chloroform und Wasser in sterilisierte Glaskolben gebracht, welche einen Watteverschluß erhielten; im Versuch 2 wurde $1 \mathrm{~g}$ Citronensäure zugesetzt. Die Autodigestion dauerte 5 Tage (Temperatur $35-40^{\circ}$ ). Nach Beendigung des Erhitzens trennten wir die Flüssigkeit vom Ungelösten und verarbeiteten sie sodann in der früher beschriebenen Weise auf Arginin. Wir erhielten dabei folgende Resultate:

Versuch I: $520 \mathrm{~g}$ frische Pflänzchen mit $102,7 \mathrm{~g}$ Trockensubstanz gaben nach der Autodigestion $0,530 \mathrm{~g}$ Argininkupfernitrat $=0,3132 \mathrm{~g}$ oder $0,31 \%$ Arginin.

Versuch II: 500 g frische Pflänzchen mit 93,93 g Trockensubstanz gaben nach der Autodigestion 0,544 g Argininkupfernitrat $=0,322 \mathrm{~g}$ oder $0,34 \%$ Arginin.

Da der Arginingehalt des für diese Versuche benutzten Materials nicht bestimmt worden ist, so läßt sich aus vorstehenden Zahlen nicht berechnen, um wieviel während der Autodigestion das Arginin an Menge zugenommen hatte. Doch sieht man, daß in diesen Versuchen die Verhältnisse für die Argininbildung nicht günstiger lagen, als in den Versuchen

1) Analytische :Belege: Das Volumen der arginin- und histidinhaltigen Lösung betrug $100 \mathrm{ccm}$. Je $30 \mathrm{ccm}$ davon gaben

a) $0,03654 \mathrm{~g} \mathrm{~N}$.

b) $0,03624 \mathrm{~g} \mathrm{~N}$. (Mittel $0,03639 \mathrm{~g} \mathrm{~N}$.). 
mit getrockneten Keimpflanzen; denn die nach der Autodigestion vorgefundene Argininmenge betrug ja in Maximo nur 0,34\% der Pflanzentrockensubstanz.

Endlich haben wir auch noch einen Autodigestionsversuch mit $50 \mathrm{~g}$ der getrockneten und mit Äther extrahierten zweitägigen Keimpflanzen ausgeführt, in welchem der Flüssigkeit durch Zusatz von etwas Soda anfangs schwach alkalische Reaktion gegeben wurde. Als Antiseptikum setzten wir Chloroform zu; die Versuchsbedingungen waren im übrigen die gleichen, wie bei den mit dem gleichen Material früher ausgeführten Versuchen. Die Autodigestion dauerte 10 Tage. Die nach Beendigung des Erhitzens vom Ungelösten getrennte Flüssigkeit wurde so verarbeitet, wie es oben angegeben worden ist. Die Stickstoffmenge in dem durch Silberlösung und Barytwasser hervorgebrachten Niederschlage betrug $0,183 \%$ der Trockensubstanz des Ausgangsmaterials. Demnach war in diesem Versuche weniger Arginin und Histidin entstanden, als in den andern Versuchen. Offenbar war der Sodazusatz der Wirkung des Enzyms nicht günstig.

Aus den im vorigen gemachten Mitteilungen ist zu ersehen, in welchem Maße während der Autodigestion das Arginin und das Histidin an Menge zugenommen hatten. Um über die gleichzeitige Bildung von Leucin und Tyrosin Aufschluß zu gewinnen, wurden noch 2 andere Versuche angestellt; als Material für dieselben dienten getrocknete und mit Äther extrahierte zweitägige Keimpflanzen. Es wäre uns erwünscht gewesen, die bei der Autodigestion stattfindende Bildung von Leucin und Tyrosin durch quantitative Bestimmungen genau verfolgen zu können; da aber für diesen Zweck geeignete Methoden nicht bekannt sind, so mußten wir uns darauf beschränken, die bei Verarbeitung der Flüssigkeiten erhaltene Ausbeute an Aminosäuren zu bestimmen.

Für den ersten dieser beiden Versuche verwendeten wir $100 \mathrm{~g}$ lufttrockenes Material mit 87,9 g Trockensubstanz. Als Antiseptikum wurde Chloroform zugesetzt; die Versuchsbedingungen (Wassermenge, Temperatur etc.) waren im übrigen die gleichen, wie früher. Die Autodigestion dauerte 7 Tage. 
Die nach Beendigung des Erhitzens vom Ungelösten getrennte Flüssigkeit wurde mit Schwefelsäure angesäuert und sodann mit Phosphorwolframsäure versetzt, der durch dieses Reagens erzeugte Niederschlag abfiltriert, das Filtrat durch Barytwasser von der überschüssigen Phosphorwolframsäure und der Schwefelsäure befreit, hierauf bei neutraler Reaktion im Wasserbade stark eingeengt und nun mit etwas konzentrierter Ammoniakflüssigkeit und so viel Weingeist versetzt, daß eine starke Fällung entstand. Die von dieser Fällung getrennte weingeistige Flüssigkeit lieferte, nachdem sie im Wasserbade zum Sirup eingedunstet worden war, eine aus Aminosäuren bestehende Ausscheidung. Letztere wurde auf einem Zeugfilter abfiltriert und mit etwas Weingeist gewaschen, das Filtrat mit mehr Weingeist und etwas Ammoniakflüssigkeit versetzt, die dadurch hervorgebrachte Fällung wieder entfernt. Die dabei übrig bleibende weingeistige Lösung lieferte nach dem Eindunsten wieder eine aus Aminosäuren bestehende Ausscheidung, welche mit der zuerst erhaltenen vereinigt wurde. Aus der dabei übrig gebliebenen Flüssigkeit konnten wir bei gleicher Behandlung noch ein drittes Mal Aminosäuren gewinnen, doch nur in sehr geringer Quantität. Die durch Aufstreichen auf eine Tonplatte von den Resten der Mutterlauge befreiten Aminosäuren wurden im Exsiccator getrocknet und sodann gewogen; ihr Gewicht betrug $1,093 \mathrm{~g}=1,25 \%$ der Trockensubstanz des Ausgangsmaterials. Das in dieser Weise erhaltene Produkt bestand allem Anschein nach nur aus Aminosäuren (Asparagin war darin nicht nachzuweisen). Aus demselben konnten leicht Tyrosin und Leucin isoliert werden. Das dabei angewendete Trennungsverfahren entsprach den früher von E. Schulze sowie auch von Butkewitsch gemachten Angaben.

In dem im vorigen beschriebenen Versuche war die Ausbeute an Aminosäuren nicht besonders hoch - vermutlich deshalb, weil ein Teil dieser Stoffe in die Fällungen über-

1) Analytische Belege: Volumen der arginin- und histidinhaltigen Flüssigkeit $=100 \mathrm{ccm}$. Je $30 \mathrm{ccm}$ davon gaben: a) $0,02396 \mathrm{~g} \mathrm{~N}$.

b) $0,02411 \mathrm{~g} \mathrm{~N}$. 
gegangen war. Eine bedeutend größere Ausbeute an Aminosäuren lieferte ein zweiter Versuch, in welchem wir die Flüssigkeit in etwas anderer Weise verarbeiteten - allerdings. war in diesem Falle die Autodigestion etwas länger, nämlich 10 Tage lang fortgesetzt worden. Für diesen Versuch verwendeten wir $150 \mathrm{~g}$ des lufttrockenen Ausgangsmaterials $=131,85 \mathrm{~g}$ Trockensubstanz. Die Versuchsbedingungen waren die gleichen wie in dem zuletzt beschriebenen Versuche, als Antiseptikum wurde Chloroform zugesetzt. Die nach Beendigung des Erhitzens vom Ungelösten getrennte Flüssigkeit versetzten wir zunächst mit Tannin, entfernten die dadurch entstandene Fällung durch Filtration und fügten dem Filtrat Bleiessig in schwachem Überschuß zu. Das Filtrat vom Bleiniederschlag wurde durch Schwefelwasserstoff vom Blei befreit, dann im Wasserbade stark eingeengt. Aus der erkalteten Flüssigkeit schied sich Tyrosin aus; die davon abfiltrierte Mutterlauge gab bei weiterem Verdunsten eine hauptsächlich aus Leucin bestehende Ausscheidung, die wir mit Hilfe eines Zeugfilters von der dickflüssigen Mutterlauge trennten und sodann auf eine Tonplatte brachten. Die Mutterlauge wurde zunächst mit konzentrierter Ammoniakflüssigkeit, dann mit soviel Weingeist versetzt, daß eine starke Fällung entstand. Die von dieser Fällung getrennte weingeistige Lösung behandelten wir dann ganz ebenso, wie die in ähnlicher Weise in dem vorher beschriebenen Versuch erhaltene Lösung. Die dabei zur Abscheidung gebrachten Aminosäuren wurden mit den zuerst erhaltenen vereinigt. Das Gewicht des in dieser Weise dargestellten Präparats betrug nach dem Trocknen 3,5 g oder ca. 2,6\% der Trockensubstanz des Ausgangsmaterials.

Das Gewicht des in diesen beiden Versuchen erhaltenen Tyrosins betrug nicht viel weniger als $1 \mathrm{~g}$. Gereinigt durch Auflösen in Ammoniak und Wiederausfällen durch Salpetersäure sowie durch Umkrystallisieren aus ammoniakhaltigem heißen Wasser bildete es weiße, glänzende Nadeln. Die Krystalle lösten sich leicht in Ammoniakflüssigkeit, sowie in verdünnten Mineralsäuren und gaben die Hoffmansche, die Piriasche und die Mörnersche Reaktion: Das Leucin 
bildete, nachdem es durch wiederholtes Umkrystallisieren aus einem Gemisch von heißem Weingeist und Ammoniakflüssigkeit gereinigt worden war, weiße, glänzende Krystallblättchen, die beim Erhitzen im Glasröhrchen sich unter Bildung eines weißen Sublimats verflüchtigten und dabei den Geruch nach Amylamin entwickelten. Sie lösten sich schwer in kaltem, leicht in kochendem Wasser; in heißem Alkohol lösten sie sich erst nach Zusatz von etwas Ammoniakflüssigkeit. Ihre heiße, wässerige Lösung gab auf Zusatz von Kupferacetat eine dem Leucinkupfer gleichende Ausscheidung.

Ein mit heißem Wasser hergestellter Auszug aus dem für die Autodigestionsversuche verwendeten Ausgangsmaterial lieferte bei der Verarbeitung nach dem beschriebenen Verfahren nur eine sehr geringe Menge von Aminosäuren; bezogen auf die Trockensubstanz des Ausgangsmaterials, betrug die Ausbeate nur ca. 0,2\%. Daraus ergibt sich aber mit Sicherheit, daß bei der Autodigestion der Keimpflanzen Leucin und Tyrosin in sehr beträchtlicher Quantität gebildet wurden. Das Gleiche ist durch die von Butkewitsch mit Keimplanzen von Lupinus luteus gemachten Versuche bewiesen worden, wie weiter oben von uns schon erwähnt wurde.

Es scheint, daß während der Autodigestion eine Bildung von Leucin und Tyrosin in stärkerem Maße erfolgt ist, als die Bildung von Arginin. Denn der Gehalt des Untersuchungsmaterials an dieser Base konnte durch die Autodigestion nur bis auf ungefähr $1 / 2 \%$ gesteigert werden, während die Ausbeute an Aminosäuren bis auf ungefähr 2,6\% stieg - obgleich ohne Zweifel bei der Abscheidung dieser letzteren Stickstoffverbindungen aus den Extrakten beträchtliche Substanzverluste nicht $\mathrm{zu}$ vermeiden waren. Diese Schlußfolgerung steht auch im Einklang mit den Resultaten der von Butkewitsch ausgeführten Autodigestionsversuche. Wie aus den oben reproduzierten Zahlen $\mathrm{zu}$ ersehen ist, war in diesen Versuchen die aus eiweißfreiem Extrakt in den Phosphorwolframsäureniederschlag eingehende Stickstoffmenge während der Autodigestion sowohl bei Lupinus angustifolius als bei Lupinus luteus nur wenig gestiegen, während dagegen die Stickstoffmenge im Filtrat vom 
Phosphorwolframsäureniederschlag sich sehr stark vermehrt hatte.

Wollte man annehmen, daß diese Stickstoffmenge ausschließlich krystallinischen Produkten, und zwar Aminosäuren, angehörte, so müßte der Gehalt der bezüglichen Extrakte an solchen Produkten ein sehr hoher gewesen sein. Doch lassen sich gegen jene Annahme Einwände erheben,; es ist möglich, daß bei der Einwirkung des proteolytischen Enzyms auf die Eiweißstoffe neben Arginin und Aminosäuren auch Produkte sich gebildet hatten, welche durch Phosphorwolframsäure nicht mehr gefällt wurden, aber noch nicht krystallinische Endprodukte der Spaltung waren.

Wenn es Verfahren gäbe, mit deren Hilfe man Leucin und Tyrosin aus den Extrakten quantitativ abscheiden und bestimmen könnte, so würde es von Interesse sein, die dabei erhaltenen Zahlen mit der Eiweißquantität $\mathrm{zu}$ vergleichen, welche während der Autodigestion gespalten worden ist; bei dieser Vergleichung würde dann auch das Resultat einer gleichzeitig ausgeführten Argininbestimmung zu berücksichtigen sein. Leider aber stehen Verfahren, mittels deren jenes Ziel sich erreichen läßt, uns zur Zeit noch nicht zur Verfügung. Die Aufgabe, den Zerfall der Eiweißstoffe in die verschiedenen krystallinischen Spaltungsprodukte mit Hilfe quantitativer Bestimmungen zu verfolgen, ließ sich also mit den augenblicklich zur Verfügung stehenden Hilfsmitteln nicht in befriedigender Weise lösen; daß aber durch das proteolytische Enzym der keimenden Samen die Eiweißstoffe in den letzteren eine weitgehende Spaltung erleiden, darüber kann nach den jetzt vorliegenden Versuchen wohl kein Zweifel mehr bestehen. Daraus folgt jedoch noch nicht, daß die Keimpflänzchen nur dieses eine Hilfsmittel zur Spaltung der Eiweißstoffe besitzen; es wäre ja möglich, daß die Eiweißspaltung durch das Enzym nur eingeleitet, dann aber durch andere Mittel weitergeführt würde. Einen derartigen Verlauf der Eiweißzersetzung während der Keimung scheint man für manche Samen, so z. B. für diejenigen der Gerste, anzunehmen. ${ }^{1}$ )

1) C. J. Lintner, Chem. Zentralbl. 1902, S. 288. 


\section{E. Normale 14tägige Pflanzen.}

Normale 14tägige Pflanzen, gewachsen im Freien bei günstiger Witterung in fruchtbarem Boden, sind von Wassilieff loc. cit. untersucht worden und zwar in der Weise, daß dieselben in Cotyledonen, Stengel, Wurzeln und Blättchen zerlegt, diese Teile sodann gesondert der qualitativen und quantitativen Untersuchung unterworfen wurden. Die quantitative Analyse hatte vorzugsweise den Zweck, die Verteilung des Stickstoffs auf die verschiedenen Stoffe und Stoffgruppen so gut zu bestimmen, wie dies mit Hilfe der verfügbaren Methoden möglich war. Das Asparagin wurde nach Sachsses Verfahren bestimmt; doch wurden die dabei erhaltenen Resultate durch Wägung der aus den Extrakten abscheidbaren Asparaginkrystalle kontrolliert.

Wir haben die von Wassilieff erhaltenen Resultate zunächst dadurch ergänzt, daß wir in den oben genannten - Objekten unter Benutzung des davon noch vorhandenen Materials den Gehalt an Arginin in der früher beschriebenen Weise bestimmten. Ferner haben wir von normalen Pflänzchen, welche in ihrem Entwicklungsgrade mit den von Wassilieff untersuchten ungefähr übereinstimmten, die Blätter abgetrennt und in Stiele und Blattspreiten zerlegt; in einem jeden dieser beiden Teile wurde dann der Asparagingehalt bestimmt. Die Resultate dieser Bestimmungen teilen wir im folgenden mit und reproduzieren zugleich die Ergebnisse der Wassilieffschen Arbeit insoweit, als dies für die weiter unten folgenden Betrachtungen erforderlich ist.

\section{Cotyledonen.}

Die Trockensubstanz der Cotyledonen enthielt:

\begin{tabular}{|c|c|}
\hline Gesamtstickstoff & $7,83 \%$ \\
\hline Pro & $14,64 \%$ mit $2,44 \%$ \\
\hline Ast & D $3,73 \%$ \\
\hline Argir & $0,14 \%, 0,045 \%$ \\
\hline
\end{tabular}

Die Cotyledonen enthielten also neben einer großen Menge von Asparagin auch ein wenig Arginin. Bei Verarbeitung des

1) $285 \mathrm{~g}$ Cotyledonentrockensubstanz gaben 0,678 g Argininkupfernitrat $=0,400 \mathrm{~g}$ Arginin. 
Phosphorwolframsäureniederschlags nach dem weiter oben besprochenen Verfahren erhielten wir auch etwas Histidindichlorid. Aus dem Gewicht des letzteren berechnet sich für die Cotyledonen ein Gehalt an Histidin, der ungefähr halb so groß ist, als der Arginingehalt. Doch schien das Histidindichlorid nicht völlig rein zu sein; denn das daraus dargestellte Histidinsilber besa $\beta$ einen hinter der Theorie etwas zurückbleibenden Silbergehalt.

Wassilieff suchte aus einem weingeistigen CotyledonenExtrakt Aminosäuren darzustellen. Da das Auskrystallisieren der letzteren durch den ziemlich beträchtlichen Zuckergehalt des Extrakts erschwert wurde, so zerstörte Wassilieff diesen Zucker durch Gärung. ${ }^{1}$ ) Es gelang dann, eine kleine Quantität von Aminosäuren zu gewinnen (ca. 0,3 g Rohprodukt aus $600 \mathrm{~g}$ Cotyledonen). Das so erhaltene Produkt schloß neben Leucin vermutlich etwas Aminovaleriansäure ein.

\section{Stengel.}

Die Trockensubstanz der Stengel enthielt:

$\begin{array}{lr}\text { Gesamtstickstoff } & 6.77 \% \\ \text { Proteinstoffe } & 9,56 \% \text { mit } 1,56 \% \mathrm{~N} \\ \text { Asparagin } & 21,12 \% \triangleright 4,48 \%\end{array}$

Aus den Stengeln vermochten wir, bei Anwendung von $420 \mathrm{~g}$ lufttrockenen Materials, kein Arginin zu isolieren; bei Verarbeitung des Phorphorwolframsäureniederschlags erhielten wir aus der durch Silberlösung und Baryt hervorgebrachten Fällung nur eine geringe Menge eines Sirups, aus welchem kein Argininnitrat auskrystallisierte. Doch gab die wässerige Lösung dieses Sirups, freilich nur schwach, die Reaktionen des Arginins; es ist also möglich, daß eine sehr geringe Menge dieser Base vorhanden war. Der Phosphorwolframsäureniederschlag lieferte dagegen eine kleine Quantität von krystallisiertem Histidindichlorid (0,322 g aus $420 \mathrm{~g}$ der lufttrockenen Stengel); doch war dieses Produkt wohl nicht ganz rein, denn der Silbergehalt des daraus dargestellten Histidinsilbers blieb um ca. 2\% hinter der Theorie zurück. Aminosäuren (Leucin etc.) vermochte Wassilieff nur in sehr kleiner Menge aus den

1, Ls ist anzunehmen, daß infolge des Hefezusatzes die Aminosäurenmenge nicht verringert, vielleicht aber ein wenig vergrößert wurde. 
Stengeln $\mathrm{zu}$ gewinnen; $700 \mathrm{~g}$ der letzteren lieferten nur $0,17 \mathrm{~g}$ Aminosäuren (Rohprodukt).

Die Stengel enthielten also neben einer sehr großen Asparaginquantität nur sehr kleine Mengen von Aminosäuren, von Arginin und von Histidin. Von Interesse ist es, noch einen Blick auf die Zahlen zu werfen, welche Wassilieff für die Verteilung des Stickstoffs auf die verschiedenen Stoffe und Stoffgruppen erhielt.

Vom Gesamtstickstoff fielen:

auf Proteinstoffe

$23,04 \%$

- Asparagin $66,17 \%$

- die aus eiweißfreiem Extrakt durch Phosphorwolframsäure fällbaren Stoffe $\quad 6,20 \%$

- andere Verbindungen (Differenz) $\quad 4,59 \%$

$$
\text { Summe } \overline{100,00 \%}
$$

Auch diese Zahlen zeigen, wie stark das Asparagin gegenüber anderen nicht proteinartigen Stickstoffverbindungen im Saft der Stengel prävalierte.

\section{Wurzeln.}

Die Trockensubstanz der Wurzeln enthielt:

$\begin{array}{ll}\text { Gesamtstickstoff } & 5,40 \% \\ \text { Proteinstoffe } & 11,22 \% \text { mit } 1,87 \% \mathrm{~N} \\ \text { Asparagin } & 10,23 \% \triangleright 2,17 \%\end{array}$

Von den Wurzeln war für die Bestimmung des Arginins kein genügendes Quantum mehr vorhanden. Es darf jedoch für wahrscheinlich erklärt werden, daß die Wurzeln in bezug auf den Arginingehalt mit den Stengeln übereinstimmten und demnach nur eine sehr geringe Menge der genannten Base enthielten. Aminosäuren fanden sich nach Wassilieff s Untersuchung in den Wurzeln nur in sehr kleiner Quantität vor.

\section{Blättchen.}

Die Trockensubstanz der Blättchen enthielt:

$\begin{array}{lr}\text { Gesamtstickstoff } & 6,57 \% \\ \text { Proteinstoffe } & 24,66 \% \text { mit } 4,11 \% \mathrm{~N} \\ \text { Asparagin } & 6,65 \% \text { \ } 1,41 \% \text { > } \\ \text { Arginin } & 0,006 \% \gg 0,002 \% \mathrm{~N} .\end{array}$


Die Blättchen enthielten also Arginin in sehr kleiner Menge. Wir mußten von diesem Material ein sehr großes Quantum anwenden, um eine für die Identifizierung genügende Argininmenge zu gewinnen; aus $900 \mathrm{~g}$ lufttrockener Blättchen erhielten wir nur $0,088 \mathrm{~g}$ Argininkupfernitrat. Histidin schien zwar in sehr kleiner Menge vorhanden zu sein; doch gelang es uns nicht, Histidinchloridkrystalle zu erhalten. Aminosäuren (Leucin usw.) vermochte Wassilieff aus den Blättchen nur in sehr kleiner Menge abzuscheiden, ein Kilogramm des lufttrockenen Materials lieferte nur 0,21 g Aminosäuren.

Die große Differenz zwischen dem Asparagingehalt der Stengel $(21,12 \%)$ und der Blättchen $(6,65 \%)$ entspricht der Annahme, daß in den Blättchen unter dem Einfluß der hier im Assimilationsprozeß gebildeten Kohlenhydrate das Asparagin in Eiweiß umgewandelt wird. In Übereinstimmung mit dieser Annahme steht die Tatsache, daß der Gehalt der Blättchen an Proteinstoffen $2^{1 / 2}$ mal so groß war, als derjenige der Stengel.

Wie schon oben erwähnt worden ist, haben wir noch von normalen 14tägigen Pflänzchen die Blätter abgetrennt, dieselben in Stiele und Blattspreiten zerlegt und jeden dieser Teile auf Asparagin untersucht. Dabei erhielten wir folgende auf die Trockensubztanz der Untersuchungsobjekte sich beziehende Zahlen.

I)ie Blattstiele enthielten

\Blattspreiten 》

$7,92 \%$ Asparagin

$2,36 \%$ ग

Auch dieser Befund steht in Einklang mit der obigen Annahme; wenn die Assimilationsprodukte die Umwandlung des Asparagins bewirken, so muß in denjenigen Teilen des Blattes, in denen der Assimilationsprozeß seinen Sitz hat, der Asparagingehalt geringer sein als im Blattstiel.

Aus den vorstehenden Zahlen berechnet sich unter Berücksichtigung des Verhältnisses, in welchem das Trockengewicht der Blattstiele zu demjenigen der Blattspreiten stand, für die ganzen Blätter ein Asparagingehalt von 3,5\%, während die von Wassilieff untersuchten Blätter 6,65\% Asparagin enthielten. Daß der Asparagingehalt dieser Organe ziemlich beträchtlichen Schwankungen unterliegen kann, ist

Hoppe-Seyler's ZZitschrift f. physiol. Chemie. XXXVIII. 
leicht $\mathrm{zu}$ verstehen; je nach der Intensität, mit welcher der Assimilationsprozeß und mit letzterem die Bildung von Eiweißstoffen auf Kosten des;Asparagins vor dem Zeitpunkt der Ernte in den Blättern verlief, vielleicht auch je nach der Tageszeit, in der die Ernte stattgefunden hat, muß die vorhandene Asparaginmenge schwanken.

Schließlich sei noch erwähnt, daß auch aus den von den Stielen getrennten Blattspreiten Asparagin in Krystallen dargestellt werden konnte, und zwar isolierten wir dasselbe aus dem Mercurinitratniederschlag. Die Krystralle stimmten sowohl im Aussehen wie in den Reaktionen mit Asparagin überein.

Die Zusammensetzung der ganzen Pflänzchen.

Aus den bei Analyse der einzelnen Pflanzenteile erhaltenen Zahlen hat Wassilieff unter Berücksichtigung des Trockengewichts jener Teile die Zusammensetzung der ganzen Pflänzchen berechnet. In entsprechender Weise haben wir noch den Arginingehalt dieser Pflänzchen berechnet, wobei wir die Annahme machten, daß die Wurzeln nicht mehr Arginin enthielten als die Stengel. ${ }^{1}$ ) Das Resultat der Berechnung teilen wir im folgenden mit und reproduzieren gleichzeitig einen Teil der von Wassilieff gefundenen Zahlen.

Die Trockensubstanz der Pflänzchen enthielt:

Gesamtstickstoff
Proteinstoffe
Asparagin
Arginin

$$
\begin{aligned}
& 6,81 \% \\
& 17,76 \% \text { mit } 2,96 \% \mathrm{~N} . \\
& 12,78 \% \triangleright 2,71 \% \\
& 0,033 \% \gg 0,01 \% \text { }
\end{aligned}
$$

Für den Arginingehalt der Pflänzchen ergibt sich also eine sehr niedrige Zahl. Daß neben dem Arginin sich auch nur eine sehr kleine Histidinmenge vorfand, ist aus den für die einzelnen Pflanzenteile gemachten Angaben $\mathrm{zu}$ ersehen. Diese Angaben zeigen, daß auch Leucin und Aminovaleriansäure in den Pflänzchen sich nur in sehr geringer Quantität vorfanden und daß aus denselben Tyrosin und Phenylalanin nicht

1) Ist diese Annahme nicht richtig, so kann dadurch doch kein großer Fehler bedingt worden sein, da das Trockengewicht der Wurzeln nur ca. $7 \%$ vom Trockengewicht der ganzen Pflänzchen betrug. 
dargestellt werden konnten. In bedeutender Menge fand sich dagegen Asparagin vor. Der Gehalt der Pflanzentrockensubstanz an diesem Amid betrug $12,78 \%$; von der auf nicht proteinartige Verbindungen fallenden Stickstoffmenge gehörten $70,4 \%$ dem Asparagin an; von dem Rest (29,6\%) wird nur ein kleiner Teil von den aus den Pflänzchen abscheidbaren Aminosäuren und Hexonbasen gedeckt; demnach müssen neben diesen Stoffen und dem Asparagin noch andere nicht proteinartige Stickstoffverbindungen in beträchtlicher Quantität vorhanden gewesen sein. Auf die Frage nach der Natur dieser Stoffe läßt sich eine genügende Antwort zur Zeit nicht geben. Allerdings ist nachgewiesen, daß außer Arginin und Histidin noch andere durch Phosphorwolframsäure fällbare krystallinische Stickstoffverbindungen, z. B. Vernin, sich vorfanden; doch betrug die Stickstoffmenge, welche in den in einem eiweißfreien Extrakt durch Phosphorwolframsäure erzeugten Niederschlag eingegangen war, nach Wassilieffs Bestimmung nur 7,63 \% des Gesamtstickstoffs. Die Unsicherheit, in der wir uns hier in bezug auf die Natur der nicht proteinartigen Stickstoffverbindungen befinden, besteht übrigens auch hinsichtlich junger, grüner Gewächse anderer Art; solche Gewächse enthalten häufig nicht proteinartige Stickstoffverbindungen in beträchtlicher Menge, ohne daß wir über die Qualität derselben genauere Angaben zu machen vermögen.

Vergleichung der normalen 14tägigen Pflänzchen mit den Pflänzchen, in denen der Assimilationsprozeß nicht stattfinden konnte.

Vergleicht man die normalen 14tägigen Pflänzchen mit den Keimpflanzen der ersten Entwicklungsperiode, so zeigt sich, daB die letzteren bedeutend reicher an Arginin und an Aminosäuren (Leucin, Tyrosin etc.) sind. Aus 4tägigen Keimpflanzen konnten wir $0,28 \%$ Arginin darstellen, aus normalen 14tägigen Pflänzchen nur $0,033 \%$; die Ausbeute an Aminosäuren war weit größer aus Keimpflanzen, deren Alter nur 7 Tage betrug, als aus den 14tägigen grünen Pfänzchen. Dagegen enthielten die letzteren ełensoviel Asparagin als die 7tägigen 
Keimpflanzen. Bemerkenswert ist, daß von der den nicht proteinartigen Verbindungen angehörenden Stickstoffmenge in den grünen Pflänzchen ungefähr $70 \%$ auf das Asparagin fielen, in den 7tägigen Keimpflanzen dagegen nur $56 \%$.

Eine Vergleichung der 14 tägigen normalen mit den 18tägigen etiolierten Pflänzchen zeigt, daß die letzteren reicher an Aminosäuren (Aminovaleriansäure und Phenylalanin) und auch etwas reicher an Arginin sind, als die grünen Pflänzchen, auch enthalten sie eine weit größere Quantität von Asparagin. Bei dieser Vergleichung muß aber berücksichtigt werden, daß in den grünen Pflänzchen im Assimilationsprozeß ein beträchtliches Quantum von Kohlenhydraten gebildet worden war, während der Kohlenhydratgehalt der etiolierten Pflänzchen während ihrer Entwicklung fortwährend abgenommen hatte; infolge davon war der Stickstoffgehalt in den letzteren auf $10,08 \%$ gestiegen, in den grünen Pflänzchen dagegen auf $6,81 \%$ gesunken; mit dem Stickstoffgehalt muß aber in jenen Pflänzchen selbstverständlich der Prozentgehalt an denjenigen Stickstoffverbindungen, die einer Zersetzung im Stoffwechsel nicht unterlagen, gestiegen sein.

Vergleicht man in den beiden Objekten die Verteilung des Gesamitstickstoffs auf die verschiedenen Stoffe und Stoffgruppen, so zeigt sich u. a., daß von 100 Teilen des Nichtproteinstickstoffs in den grünen Pflänzchen ca. 70 Teile auf Asparagin fallen, in den etiolierten dagegen 65 Teile. In den 7tägigen Keimpflanzen gehörten, wie oben schon erwähnt ist, nur 56 Teile des "Nichtproteinstickstoffs » dem Asparagin an. Während der Entwicklung der Pflänzchen am Licht hatte also das Mengenverhältnis zwischen dem Asparaginstickstoff und der auf andere nichtproteinartige Verbindungen fallenden Stickstoffmenge sich zugunsten des ersteren verschoben, so daß man denken könnte, es seien die letzteren Verbindungen für die Eiweißsynthese in den ergrünten Pflänzchen in stärkerem Maße verwendet worden, als das Asparagin.

Diese auch an einigen anderen Objekten hervorgetretene Erscheinung muß auffallen im Hinblick auf die unseres Wissens sehr verbreitete Ansicht, daß gerade das Asparagin eine für 
die Eiweißsynthese sehr geeignete Stickstoffverbindung ist — eine Ansicht, die auch, wie oben dargelegt ist, eine Stütze in den Beobachtungen findet, welche über die Verteilung des Asparagins auf die verschiedenen Organe der grünen Pflänzchen von Lupinus albus gemacht worden sind. Der anscheinende Widerspruch verschwindet, wenn man der von E. Schulze aus seinen Untersuchungen abgeleiteten Schlußfolgerung zustimmt, daß in den Keimpflanzen Asparagin auf Kosten anderer Produkte des Eiweißumsatzes gebildet werden kann. Ist dies der Fall, so kann trotz des Verbrauchs von Asparagin in den Blättchen und anderen im Wachstum begriffenen Pflanzenteilen die vorhandene Asparaginquantität eine Zunahme erfahren, weil während der Zuleitung der Eiweißzersetzungsprodukte nach den Verbrauchsorten Asparagin sich bildet.

Man hat anzunehmen, daß die Bildung von Asparagin auf Kosten anderer Produkte des Eiweißumsatzes sowohl in den etiolierten als in den normalen, grünen Pflänzchen erfolgt. In den letzteren scheint dieser Prozeß besonders leicht und vollständig sich vollziehen zu können, denn aus ihnen erhielt man Aminosäuren und Hexonbasen in geringerer Quantität als aus den etiolierten Keimpflanzen.

Es ist von Interesse, mit den normalen 14 tägigen Pflänzchen hinsichtlich des Stoffgehalts auch noch Pflänzchen von Lupinus albus zu vergleichen, die zwar bei Lichtzutritt, aber an einem schattigen Orte in reinem Sande gezogen und nur sehr langsam gewachsen waren. (Es hatte sich an ihnen nur das erste Blättchenpaar entwickelt.) Aus diesen Pflänzchen konnte man Aminosäuren (Leucin und Aminovaleriansäure) in relativ beträchtlicher Quantität darstellen. Die Umwandlung der primären Eiweißzersetzungsprodukte in andere Verbindungen scheint also in diesen Pflänzchen infolge der Umstände, unter denen letztere sich entwickelten, weit langsamer stattgefunden zu haben, als in den normalen 14 tägigen Pflänzchen, auf welche die weiter oben gemachten Angaben sich beziehen. 


\section{Schlußbetrachtungen und Zusammenfassung der Resultate.}

Den Untersuchungen, deren Ergebnisse in dieser Abhandlung mitgeteilt worden sind, lag das Bestreben zugrunde, einen möglichst weitgehenden Einblick in die in den Keimpflanzen von Lupinus albus vor sich gehenden Umwandlungen stickstoffhaltiger Stoffe zu gewinnen. Dazu mußten diese Keimpflanzen in verschiedenen Entwicklungsstadien einer qualitativen und quantitativen Untersuchung unterworfen werden. Die dabei gewonnenen Resultate weisen noch manche Lücken auf, zu deren Ausfüllung neue Versuche erforderlich sind; auch kommt den von uns gemachten Quantitätsangaben zum Teil kein hoher Grad von Genauigkeit zu, wie weiter oben schon hervorgehoben worden ist. Indessen lassen sich doch jene Resultate im Verein mit den Ergebnissen früher ausgeführter Untersuchungen zur Ableitung einer Anzahl von Schlußfolgerungen verwenden Schlußfolgerungen, die sich freilich zum großen Teil schon in den oben citierten Abhandlungen E. Schulzes finden.

In den unter Lichtabschluß sich entwickelnden Keimpflanzen von Lupinus albus nimmt mit dem Fortschreiten des Wachstums der Gehalt an Proteinstoffen immer mehr ab. Gleichzeitig erfolgt eine stetige Zunahme des Asparagingehalts. Während 4tägige Pflänzchen 3,11, 7 tägige 12,78\% Asparagin enthielten, war der Gehalt an diesem Amid in den 18tägigen etiolierten Pfänzchen auf 25,7\% gestiegen (ein ähnliches Ansteigen des Asparagingehaltes ist bei andern Lupinusarten beobachtet worden. ${ }^{1}$ ) Ganz anders, wie mit dem Asparagin, verhält es sich mit dem Tyrosin, dem Leucin und dem Arginin. Tyrosin fand sich in den ältern etiolierten Pflänzchen in weit geringerer Quantität vor, als in den Pflänzchen der ersten Entwicklungsperiode, und nahm also während der Weiterentwicklung der Pflänzchen an Menge ab. Daß das Gleiche für das Leucin anzunehmen ist, wurde oben im Abschnitt B

1) Man vergleiche z. B. die von M. Merlis (Landw. Versuchsstationen, Bd. 48, S. 419) an Keimpflanzen von Lupinus angustifolius gemachten Beobachtungen. 
gezeigt. Für den Gehalt der Pflanzentrockensubstanz an Arginin wurden folgende Zahlen gefunden:

$\begin{array}{rll}\text { Ungekeimte Samen } & 0,019 \%, \\ 2 \text { tägige Keimpflanzen } & 0,10 \%, \\ 4 & \searrow & 0,25 \% \text { (Mittelzahl), } \\ 6 & \searrow & 0,13 \% \\ 18 & \searrow & 0,13 \% \text { (Mittelzahl). }\end{array}$

Das Arginin nahm also im Beginn der Keimung an Menge zu, später dagegen wieder $a b$.

Diese Wahrnehmungen führen zu der Schlußfolgerung, daß das Tyrosin, das Leucin und das Arginin im Stoffwechsel der Keimpflanzen dem Verbrauche unterliegen. Eine Stütze für diese Schlußfolgerung haben auch die Autodigestionsversuche geliefert; denn es konnte gezeigt werden, daß während der Autodigestion - ohne Zweifel durch die Wirkung des proteolytischen Enzyms der gekeimten Samen - das Tyrosin, das Leucin und das Arginin an Menge zunahmen. Daß dieses Enzym auch in den lebenden Keimpflanzen seine Wirksamkeit ausübt, aber eine sehr starke Vermehrung des Gehalts der Pflänzchen an Tyrosin, an Leucin und an Arginin nicht hervorzubringen vermag, weil diese Stoffe dem Verbrauche unterliegen, das ist eine Annahme, gegen welche kaum Einspruch erhoben werden wird.

Ein Verbrauch von Tyrosin, Leucin und Arginin kann durch die Verwendung dieser Stoffe für die Regeneration von Eiweißsubstanzen in den wachsenden Teilen der Pflänzchen bedingt sein. Doch kann darin nicht der Hauptgrund für die Verminderung jener Stoffe liegen; denn der Eiweilgehalt der unter Lichtabschluß sich entwickelnden Pflänzchen nimmt stetig $a b$, weil in ihnen der Eiweißzerfall weit stärker ist, als die Neubildung von Eiweißstoffen; auch würde man, um in jenem Prozeß die Ursache für die Abnahme des Tyrosins, des Leucins und des Arginins erblicken zu können, die unwahrscheinliche Annahme machen müssen, daß diese Stoffe ein weit besseres Material für die Eiweißregeneration sind, als das Asparagin. Man wird also zu der Schlußfolgerung gedrängt, daß im Stoffwechsel der Keimpflanzen Tyrosin, Leucin und Arginin der 
Zersetzung (dem Abbau) unterliegen. Doch ist nicht anzunehmen, daß diese Zersetzung bis zur Entwicklung von freiem Stickstoff geht; denn eine Verminderung der absoluten Stickstoffmenge während der Keimung der Lupinensamen konnte nicht nachgewiesen werden. In welcher Weise etwa der Abbau dieser primären Eiweißzersetzungsprodukte im Stoffwechsel der Pflänzchen sich zu vollziehen vermag, darüber sind in der Einleitung dieser Abhandlung einige Bemerkungen gemacht worden, auch wurde dort R. Bertels Angabe über den Abbau des Tyrosins erwähnt.

Wenn die Keimpflanzen unter Bedingungen, die für ihr Wachstum günstig sind, sich am Licht entwickeln, so sinkt ihr Eiweißgehalt nicht auf einen so niedrigen Betrag, wie bei der Entwicklung im Dunkeln, weil nach Entfaltung der Blättchen unter Mitwirkung der im Assimilationsprozeß entstandenen Kohlenhydrate die Regeneration von Eiweißstoffen in starkem Maße stattfinden kann. Doch bewahren auch solche Pflänzchen lange einen hohen Gehalt an Asparagin. Die 14 tägigen normalen Pflanzen von Lupinus albus enthielten nach Entfaltung von 5 Laubblättchen noch 12,78\% Asparagin; nicht weniger als 39,8\% des Gesamtstickstoffs gehörten in ihnen diesem Amid an. Dagegen ließ sich aus diesen Pflänzchen nur eine sehr geringe Quantität von Aminosäuren darstellen, viel weniger als aus den 18 tägigen etiolierten Pflänzchen, die neben Leucin eine ziemlich beträchtliche Menge von Aminovaleriansäure und Phenylalanin enthielten; der Arginingehalt jener Pflänzchen wurde nur $=0,033 \%$ gefunden; auch Histidin fand sich in ihnen nur in sehr kleiner Menge vor. In diesem Falle ließe sich zwar der niedrige Gehalt an den genannten Eiweißzersetzungsprodukten eher als bei den etiolierten Pflänzchen aus einer Verwendung dieser Produkte für die Regeneration von Eiweißstoffen erklären; doch würde diese Erklärung auch hier wieder die Annahme involvieren, daß jene Produkte für die Eiweißregeneration ein besseres Material seien, als das Asparagin. Nun sprechen aber außer andern Wahrnehmungen auch die an den 14 tägigen normalen Pflanzen von Lupinus albus in bezug auf die Verteilung des Asparagins auf die ver- 
schiedenen Organe gemachten Beobachtungen auf das bestimmteste dafür, daß gerade das Asparagin eine für die Eiweißbildung in der Pflanze leicht verwendbare Stickstoffverbindung ist. Von Belang ist insbesondere die Tatsache, daß die Blättchen, in denen nach allgemeiner Annahme sehr starke Eiweißbildung erfolgt, einen sehr viel geringeren Asparagingehalt besaßen, als die Stengel, und daß in den Blattstielen 7,92\% Asparagin gefunden wurden, in den Blattspreiten dagegen nur 2,36\%. ${ }^{1}$ ) Will man überhaupt aus der Verteilung des Asparagins innerhalb der Pflänzchen einen Schluß ableiten, so wird man zu der Annahme gelangen müssen, daß das Asparagin ein für die Eiweißbildung sehr geeignetes Material ist. Daß trotzdem die ergrünten Keimpflanzen auch unter Verhältnissen, welche günstig für die Eiweißbildung sind, sich lange einen hohen Asparagingehalt bewahren, während die in der ersten Entwicklungsperiode in beträchlicher Menge auftretenden Aminosäuren und das Arginin bis auf einen kleinen Rest verschwinden, dafür hat man eine Erklärung, wenn man annimmt, daß nicht nur in den etiolierten, sondern auch in den grünen Pflänzchen, in letzteren sogar in noch stärkerem Maße, ein Abbau jener primären Eiweißzersetzungsprodukte erfolgt und daß ein dabei entstandenes stickstoffhaltiges Abbauprodukt (Ammoniak?) zur synthetischen Bildung von Asparagin verwendet wird. Ist dies der Fall, so braucht trotz der Verwendung zur Eiweißbildung das Asparagin in den Pflänzchen nicht an Menge abzunehmen, weil seinem Verbrauche die Neubildung auf Kosten anderer Produkte des Eiweißumsatzes entgegensteht. Diese Anschauungen sind früher schon von E. Schulze ausgesprochen worden; $\mathrm{zu}$ ihrer Begründung sind aber die jetzt vorliegenden Versuchsergebnisse recht geeignet; denn keine der früher als Untersuchungsobjekte benutzten Keimplanzenarten ist in so verschiedenen Entwicklungsstadien untersucht worden, wie jetzt die Keimpflanzen von Lupinus albus.

1) Während aus den verkümmerten Blättchen etiolierter Keimpflanzen von Lupinus albus sich mehr als $17 \%$ Asparagin gewinnen ließen. 
Es sei schließlich noch daran erinnert, daß durch quantitative Untersuchung von Lupinuskeimpflanzen die Bildung von Asparagin auf Kosten anderer Produkte des Eiweißumsatzes bestimmt nachgewiesen werden konnte. ${ }^{1}$ ) Dieser Prozeß ist also keineswegs nur hypothetisch; inwieweit an demselben aber die verschiedenen Aminosäuren und Hexonbasen sich beteiligen, ist schwierig $\mathrm{zu}$ entscheiden, weil neben den genannten Stickstoffverbindungen noch andere, deren Natur bis jetzt nicht aufgeklärt ist, in den Keimpflanzen in bedeutender Quantität sich finden. Dies ist ein Umstand, auf welchen E. Schulze früher schon aufmerksam gemacht hat.

Eine Bestätigung der Schlußfolgerung, die in bezug auf die Entstehung des Asparagins in den Keimpflanzen im vorigen und in den oben citierten Abhandlungen E. Schulzes ausgesprochen worden ist, lieferten die erst nach dem Niederschreiben unserer Abhandlung uns bekannt gewordenen Untersuchungen über die Zersetzung und Neubildung der Eiweißkörper in der Pflanze von G. Balicka-Iwanowska. ${ }^{2}$ ) Auch diese Untersuchungen führten $\mathrm{zu}$ dem Resultat, daß im Laufe der Zersetzung der Eiweißkörper Asparagin als sekundäres Produkt entsteht und daß als primäre Produkte Aminosäuren und Hexonbasen gebildet werden.

\section{Analytische Belege.}

Im folgenden teilen wir die analytischen Belege nur insoweit mit, als dieselben nicht schon vorher in den Text eingefügt worden sind. Die Stickstoffbestimmungen wurden sämtlich nach der Methode von Kjeldahl ausgeführt. Für jede Stickstoffbestimmung wurde in der Regel ein Gramm lufttrockene Substanz verwendet; der Kürze halber geben wir im folgenden nur die Trockensubstanzmenge an, die in dem angewendeten Quantum lufttrockener Substanz enthalten war.

1) Man vergl. diese Zeitschrift, Bd. XXIV, S. 63-70.

2) Chemisches Zentralblatt, 1903, Bd. 1, S. 847, Referat nach Anz. Akad. Wiss. Krakau 1903, 9-32. Jan. [5/1]. 


\section{Bestimmung des Gesamtstickstoffs.}

\begin{tabular}{|c|c|c|c|}
\hline $\begin{array}{l}\text { ägige Keimpflanzen, } \\
\text { entfettet }\end{array}$ & 0,8971 & g Trockensubs. & $0,07502 \mathrm{~g}=8,36 \% \mathrm{~N}$ \\
\hline Desgleichen & 0,8971 & $>$ & $0,07502=8,36 \%$ \\
\hline 4tägige Keimpflanzen & 0,9407 & 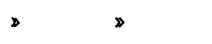 & $0,07861 \gg=8,35 \%$ \\
\hline Desgleichen & 0,9407 & D & $0,07891>=8,39 \%$ \\
\hline 11 tägige Keimpflanzen & 0,8907 & $\gg$ & $0,08131 \gg=9,12 \%$ \\
\hline Desgleichen & 0,8907 & $>$ & $0,08131 \gg=9,12 \%$ \\
\hline 18tägige Keimpflanzen & 0,9190 & D & $0,09254>=10,06 \%$ \\
\hline Desgleichen & 0,9190 & > & $0,09284>=10,10 \%$ \\
\hline
\end{tabular}

Bestimmung des Proteinstickstoffs nach Stutzers Methode.

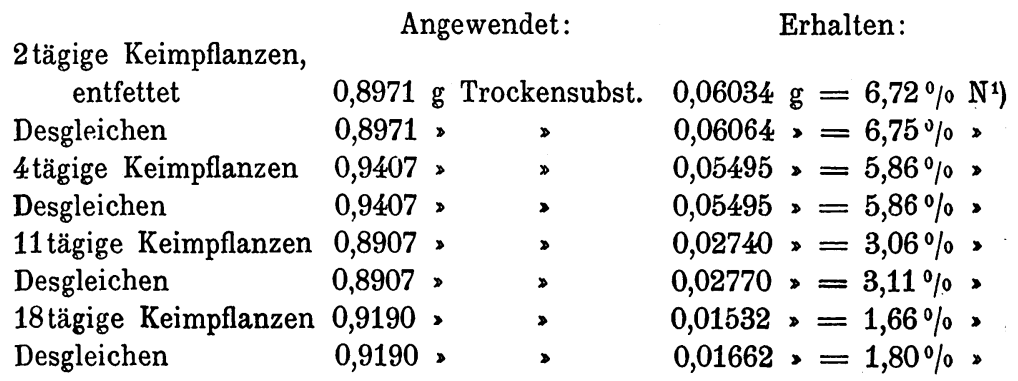

Bestimmung des Proteinstickstoffs in den unter Alkohol entwässerten und sodann über Schwefelsäure getrockneten Pflänzchen.

Bei Ausführung dieser Bestimmungen mußte auch der Stoffgehalt der Lösung, die beim Übergießen der Keimpflanzen mit Weingeist sich gebildet hatte, berücksichtigt werden. $\mathrm{Zu}$ der für die Bestimmung abgewogenen Quantität (je $1 \mathrm{~g}$ ) der lufttrockenen Substanz, im folgenden mit A bezeichnet, wurde der Verdampfungsrückstand des entsprechenden Anteils der weingeistigen Lösung, im folgenden mit B bezeichnet, hinzugefügt; dann wurde die Bestimmung nach Stutzers Verfahren ausgeführt.

1) Die für den Proteingehalt der Pflänzchen angegebenen Zahlen wurden durch Multiplikation der obigen Zahlen mit 6 erhalten. 
4tägige Keimpflanzen: Angewendet wurden 0,9156 g Trockensubstanz von $\mathrm{A}+0,1765 \mathrm{~g}$ Trockensubstanz von $\mathrm{B}=1,0921 \mathrm{~g}$ Trockensubstanz. Erhalten wurden a) $0,06668 \mathrm{~g} \mathrm{~N}$; b) 0,06683 g N, im Mittel $0,06676 \mathrm{~g}=6,11 \% \mathrm{~N}$.

11 tägige Keimpflanzen: Angewendet wurden $0,8878 \mathrm{~g}$ Trockensubstanz von $\mathrm{A}+0,2308 \mathrm{~g}$ Trockensubstanz von $\mathrm{B}=1,1186 \mathrm{~g}$ Trockensubstanz. Erhalten wurden a) $0,03683 \mathrm{~g} \mathrm{~N}$, b) $0,03683=3,29 \% \mathrm{~N}$.

Asparaginbestimmung nach Sachsses Methode.

Die Bestimmungen wurden so ausgeführt, wie es in dieser Zeitschrift, Bd, XXIV, S. 40 angegeben ist.

4tägige Keimpflanzen: Angewendet 4,703 g Trockensubstanz, Volumen des Extrakts $=300 \mathrm{ccm} ; 100 \mathrm{ccm}$ davon gaben nach dem Kochen mit Salzsäure a) 0,01048 g N, b) 0,01033 g N, im Mittel 0,01041 g $=0,66 \% \mathrm{~N}=3,11 \%$ Asparagin.

Vor dem Kochen mit Salzsäure enthielt der Extrakt eine so geringe Ammoniakmenge, daß dieselbe unberücksichtigt bleiben konnte.

18tägige Keimpflanzen: Angewendet 4,700 g Trockensubstanz, Volumen des Extrakts $=300 \mathrm{ccm} ; 100 \mathrm{ccm}$ davon gaben a) $0,04777 \mathrm{~g} \mathrm{~N}$, b) $0,04800 \mathrm{~g} \mathrm{~N}$, im Mittel $0,04789 \mathrm{~g}=3,06 \% \mathrm{~N}$. Davon ist abzuziehen die vor dem Kochen mit Salzsäure in Ammoniakform vorhandene Stickstoffmenge, welche $=0,34 \%$ gefunden wurde. Es bleiben also 2,72\% N für das beim Kochen mit Salzsäure enstandene Ammoniak.

14tägige normale Pflanzen, Blattspreiten: Angewendet $4,81 \mathrm{~g}$ Trockensubstanz, Volumen des Extrakts $=400 \mathrm{ccm} ; 100 \mathrm{ccm}$ davon gaben nach dem Kochen mit Salzsäure 0,0030 $\mathrm{g}=0,25 \% \mathrm{~N}$.

14tägige normale Pflanzen, Blattstiele: Angewendet 2,862 g Trockensubstanz, Volumen des Extrakts $=400 \mathrm{ccm} ; 100 \mathrm{ccm}$ davon gaben nach dem Kochen mit Salzsäure $0,0060 \mathrm{~g}=0,84 \% \mathrm{~N}$.

Ammoniak fand sich in diesen beiden Extrakten vor dem Kochen mit Salzsäure nur in einer nicht in Betracht kommenden Quantität vor. 